Magnetic entropy change involving martensitic transition in NiMn-based Heusler alloys

This content has been downloaded from IOPscience. Please scroll down to see the full text. 2013 Chinese Phys. B 22037505

(http://iopscience.iop.org/1674-1056/22/3/037505)

View the table of contents for this issue, or go to the journal homepage for more

Download details:

IP Address: 159.226.35.189

This content was downloaded on 20/12/2013 at 14:00

Please note that terms and conditions apply. 


\title{
Magnetic entropy change involving martensitic transition in NiMn-based Heusler alloys*
}

\author{
Hu Feng-Xia(胡凤霞) ${ }^{\dagger}$ Shen Bao-Gen(沈保根), and Sun Ji-Rong(孙继荣) \\ State Key Laboratory for Magnetism, Institute of Physics, Chinese Academy of Sciences, Beijing 100190, China
}

(Received 25 January 2013)

\begin{abstract}
Our recent progress on magnetic entropy change $(\Delta S)$ involving martensitic transition in both conventional and metamagnetic NiMn-based Heusler alloys is reviewed. For the conventional alloys, where both martensite and austenite exhibit ferromagnetic (FM) behavior but show different magnetic anisotropies, a positive $\Delta S$ as large as $4.1 \mathrm{~J} \cdot \mathrm{kg}^{-1} \cdot \mathrm{K}^{-1}$ under a field change of 0-0.9 $\mathrm{T}$ was first observed at martensitic transition temperature $T_{\mathrm{M}} \sim 197 \mathrm{~K}$. Through adjusting the Ni:Mn:Ga ratio to affect valence electron concentration $e / a, T_{\mathrm{M}}$ was successfully tuned to room temperature, and a large negative $\Delta S$ was observed in a single crystal. The $-\Delta S$ attained $18.0 \mathrm{~J} \cdot \mathrm{kg}^{-1} \cdot \mathrm{K}^{-1}$ under a field change of $0-5 \mathrm{~T}$. We also focused on the metamagnetic alloys that show mechanisms different from the conventional ones. It was found that post-annealing in suitable conditions or introducing interstitial $\mathrm{H}$ atoms can shift the $T_{\mathrm{M}}$ across a wide temperature range while retaining the strong metamagnetic behavior, and hence, retaining large magnetocaloric effect (MCE) and magnetoresistance (MR). The melt-spun technique can disorder atoms and make the ribbons display a $B 2$ structure, but the metamagnetic behavior, as well as the MCE, becomes weak due to the enhanced saturated magnetization of martensites. We also studied the effect of $\mathrm{Fe} / \mathrm{Co}$ co-doping in $\mathrm{Ni}_{45}\left(\mathrm{Co}_{1-x} \mathrm{Fe}_{x}\right)_{5} \mathrm{Mn}_{36.6} \mathrm{In}_{13.4}$ metamagnetic alloys. Introduction of $\mathrm{Fe}$ atoms can assist the conversion of the $\mathrm{Mn}-\mathrm{Mn}$ coupling from antiferromagnetic to ferromagnetic, thus maintaining the strong metamagnetic behavior and large MCE and MR. Furthermore, a small thermal hysteresis but significant magnetic hysteresis was observed around $T_{\mathrm{M}}$ in $\mathrm{Ni}_{51} \mathrm{Mn}_{49-x} \mathrm{In}_{x}$ metamagnetic systems, which must be related to different nucleation mechanisms of structural transition under different external perturbations.
\end{abstract}

Keywords: magnetic entropy change, martensitic transition, NiMn-based Heusler alloys

PACS: $75.30 . \mathrm{Sg}, 75.50 . \mathrm{Bb}$

DOI: $10.1088 / 1674-1056 / 22 / 3 / 037505$

\section{Introduction}

Magnetic refrigeration based on the magnetocaloric effect (MCE) has attracted much attention due to its superiority over gas refrigeration with regard to both energy conservation and environmental concerns. A study of MCE based on various magnetic solids is gaining worldwide attention. ${ }^{[1-4]}$ Many materials with first-order magnetic phase transition, such as $\mathrm{Gd}_{5}(\mathrm{Si}, \mathrm{Ge})_{4},{ }^{[5]} \mathrm{La}(\mathrm{Fe}, \mathrm{Si})_{13},{ }^{[4,6-9]} \mathrm{MnFeP}_{1-x} \mathrm{As}_{x},{ }^{[10]}$ and $\mathrm{Ni}-\mathrm{Mn}-\mathrm{Ga}^{\left[{ }^{[1-16]}\right.}$ have been found to exhibit great MCE. Among them, the $\mathrm{LaFe}_{1-x} \mathrm{Si}_{x}$-based alloys including $\mathrm{H} / \mathrm{C}$ interstitial compounds ${ }^{[4,6-9,17-22]}$ and NiMn-based Heusler alloys $^{[1-15,23-33]}$ have been a focus of studies in recent years. For our work on the $\mathrm{LaFe}_{1-x} \mathrm{Si}_{x}$-based alloys, review articles have already been published. ${ }^{[4,9]}$ Here we mainly review our recent progress for NiMn-based Heusler alloys.

The $X_{2} Y Z$ Heusler alloys with $L 2_{1}$ structure have attracted lots of attention since the discovery of the first ferromagnetic (FM) copper-manganese-based "alloys" by Heusler et al. in $1903{ }^{[34]}$ Later, the $\mathrm{Ni}_{2} \mathrm{MnGa}$ alloy was reported in 1960 to exhibit FM properties, ${ }^{[35]}$ and the highly ordered $L 2_{1}$ structure was confirmed by neutron diffraction measurements. ${ }^{[36]}$
The degree of order was found to be highest upon annealing at $800{ }^{\circ} \mathrm{C}$ followed by quenching. ${ }^{[37]}$ The $L 2_{1}$-type Heusler structure, shown in Fig. 1, can be considered as four interpenetrating face-centered cubic (fcc) sublattices with atoms $A$, $B, C, D$. In $\mathrm{Ni}_{2} \mathrm{MnGa}, \mathrm{Ni}$ atoms occupy $A$ and $C$ sites, and $\mathrm{Mn}$ and Ga occupy $B$ and $D$ sites, respectively. Researches have indicated that the stoichiometric $\mathrm{Ni}_{2} \mathrm{MnGa}$ can be considered to be a local moment magnet and the magnetization is mainly confined on the $\mathrm{Mn}$ atoms ${ }^{[38]}$ where the distance between $\mathrm{Mn}-\mathrm{Mn}$ nearest neighbors is about $0.4119 \mathrm{~nm}$, and the Ruderman-Kittel-Kaeya-Yo exchange interaction mediated by the conduction electrons is responsible for the FM ordering. Similar to $\mathrm{Ni}_{2} \mathrm{MnGa}$, alloying $\mathrm{Ni}_{2} \mathrm{MnZ}$ with other $Z$ elements, such as $Z=\mathrm{Sn}$, In, Sb, In, can also form a highly ordered $L 2_{1}$ structure, and rich variations of magnetic properties have been observed, particularly for the off-stoichiometric compositions. With decreasing temperature, the alloys undergo a martensitic transformation and the product shows a variety of structures depending on both the composition and the preparation process, such as $L 1_{0}$ tetragonal structure and $5 M / 7 M$ modulated structures. The reduction of the struc-

*Project supported by the National Natural Science Foundation of China (Grant Nos. 51271196, 11274357, and 51021061), the Key Research Program of the Chinese Academy of Sciences, the National Basic Research Program of China (Grant No. 2010CB833102), and the Hi-Tech Research and Development Program of China (Grant No. 2011AA03A404).

†Corresponding author. E-mail: fxhu@iphy.ac.cn

(C) 2013 Chinese Physical Society and IOP Publishing Ltd

http://iopscience.iop.org/cpb http://cpb.iphy.ac.cn 
tural symmetry affects the material's magnetic behavior fundamentally, and thus, the martensitic state, in most cases, displays magnetic properties quite different from its parent phase. The structural and magnetic properties simultaneously changed at the transition are expected to influence the MCE of the alloys strongly. In 2000, we reported a positive entropy change involving a martensitic transition at $197 \mathrm{~K}$ in a polycrystalline alloy $\mathrm{Ni}_{51.5} \mathrm{Mn}_{22.7} \mathrm{Ga}_{25.8} \cdot{ }^{[11]}$ Since then, lots of attention has been attracted to the study of MCE in NiMnbased Heusler alloys, ${ }^{[13-15,23-33]}$ and a number of papers have been published, including some review articles. ${ }^{[1-3,16]}$ Here, we mainly review our recent progress in understanding the effects of atomic substitution, post-annealing, the introduction of interstitial atoms, and forced atomic disorder on the magnetic, magnetocaloric, and transport properties for both conventional and novel metamagnetic NiMn-based Heusler alloys.

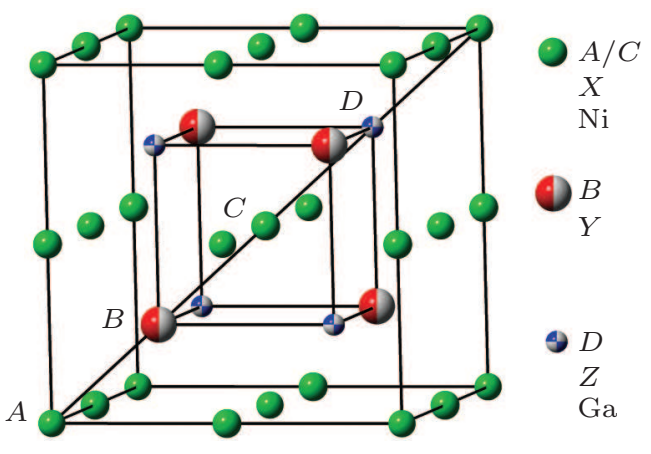

Fig. 1. The Heusler $L 2_{1}$ structure.

\section{Magnetic entropy change in conventional NiMn-based Heusler alloys}

A considerable amount of research has been focused on the stoichiometric Heusler alloys $\mathrm{Ni}_{2} \mathrm{MnGa}$ with the compositions near the 2:1:1 ratio mainly because of their unusual properties: large magnetostrictions, superelasticity, and FM shape memory effect. For these compositions, the structural transformation is usually followed by FM-paramagnetic (PM) transitions with increasing temperature. The conventional NiMnbased Heusler alloys, in both $M-H$ martensite and austenite states, display FM properties, but their magnetic anisotropies differ greatly. The austenite state is the magnetically soft phase because of its cubic structure, while the $M-H$ martensite state shows a strong anisotropy due to an asymmetrical structure transformation. The FM shape memory effect arises from the twin boundary motion in the $M-H$ martensite, which relies on a strong magnetoelastic coupling that is due to the long-range FM ordering. The magnetic anisotropy energy, $K$, can measure the magnetoelastic coupling. When $K$ is large, an external magnetic field motivates twin variants by aligning their rotation with the applied field. As a result, a considerable shape memory is generated. Generally, the field-driven strain can be as large as $10 \%$ for the conventional Ni-Mn-Ga systems. ${ }^{[16]}$ The fundamental change of magnetic properties caused by the magnetic anisotropy across the martensitic transformation is accompanied by a magnetic entropy change $(\Delta S)$.

In 2000, we reported a positive $\Delta S$ in the polycrystalline alloy $\mathrm{Ni}_{51.5} \mathrm{Mn}_{22.7} \mathrm{Ga}_{25.8}$ with a martensitic transition at $197 \mathrm{~K}$ $\left(T_{\mathrm{M}}\right) .{ }^{[11]}$ The alloy was prepared by an arc-melting technique. Powder X-ray diffraction indicated that the parent phase has the $L 2_{1}$ structure while the martensitic phase displays a tetragonal structure. Figure 2 shows the isothermal magnetization ( $M-H$ curves) measured at temperatures around $T_{\mathrm{M}}$. One can find that both the martensite and the austenite show FM properties but the field dependency of magnetization changes greatly across the transition. During the martensitic transformation, the tetragonal unit cell expands along the $c$ axis and contracts in the other two directions. The lower symmetry of the martensitic phase enhances the magnetocrystalline anisotropy, and due to the magnetoelastic interaction, the elastic energy stored by martensite gives rise to the magnetic anisotropy, which dominates the magnetization process, ${ }^{[39]}$ so the magnetization of martensite is harder to saturate than that of austenite. The interesting magnetic behavior leads to the appearance of crossing points in the $M-H$ curves measured at different temperatures. The location of the crossing points varies depending on the composition. For polycrystalline $\mathrm{Ni}_{51.5} \mathrm{Mn}_{22.7} \mathrm{Ga}_{25.8}$, it is located at $0.9 \mathrm{~T}$. According to Maxwell's relation ${ }^{[1-4]} \Delta S(T, H)=\mu_{0} \int_{0}^{H}(\partial M / \partial T)_{H} \mathrm{~d} H$, we obtain a positive entropy change and the value is $\sim$ $4.1 \mathrm{~J} \cdot \mathrm{kg}^{-1} \cdot \mathrm{K}^{-1}$ under a field change of $0-0.9 \mathrm{~T}$ (see Fig. 3). The origin of the large $\Delta S$ in $\mathrm{Ni}_{51.5} \mathrm{Mn}_{22.7} \mathrm{Ga}_{25.8}$ is attributable to the considerable magnetization jump caused by the change of the magnetocrystalline anisotropy due to the martensiticaustenitic structure transition. Furthermore, we find that the thermal hysteresis is $\sim 10 \mathrm{~K}$ for $\mathrm{Ni}_{51.5} \mathrm{Mn}_{22.7} \mathrm{Ga}_{25.8}$, and the $M-H$ curves are essentially reversible in both the martensitic and the austenitic states.

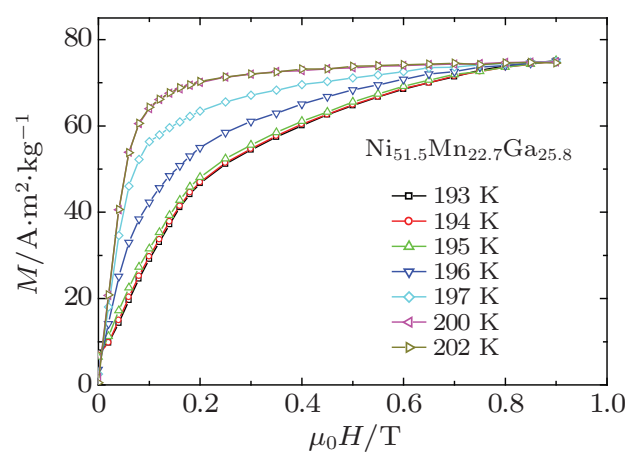

Fig. 2. Isothermal $M-H$ curves at different temperatures for polycrystalline $\mathrm{Ni}_{51.5} \mathrm{Mn}_{22.7} \mathrm{Ga}_{25.8}{ }^{[11]}$ 


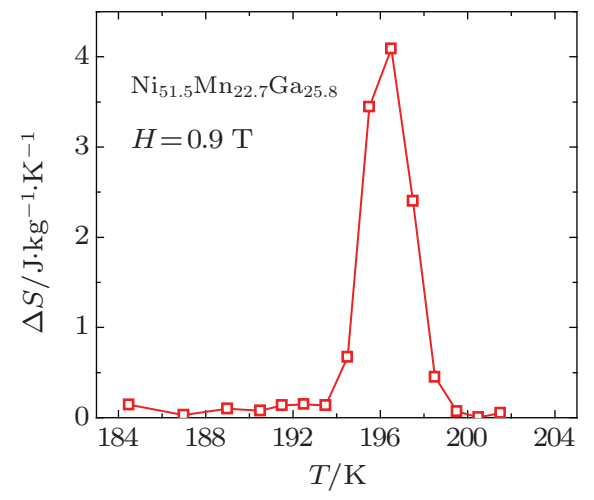

Fig. 3. Temperature dependent magnetic entropy change $\Delta S$ under a field change of $0-0.9 \mathrm{~T}$ for polycrystalline $\mathrm{Ni}_{51.5} \mathrm{Mn}_{22.7} \mathrm{Ga}_{25.8}{ }^{[11]}$

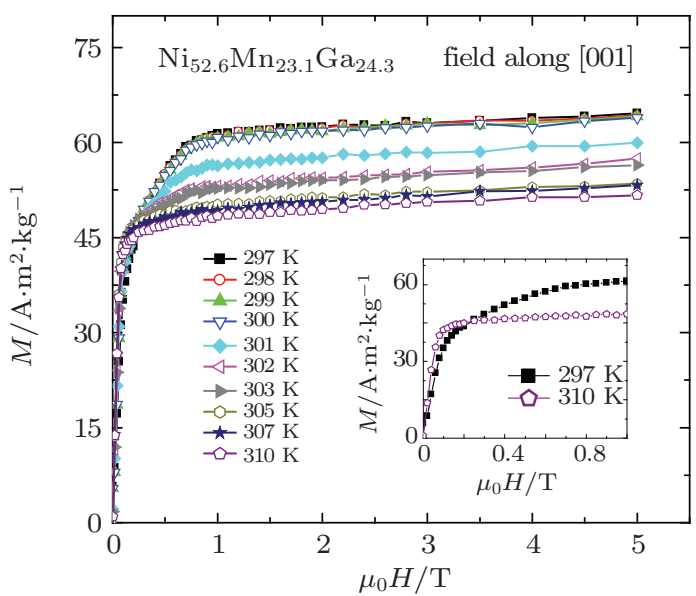

Fig. 4. Isothermal $M-H$ curves with magnetic field along the [001] direction at different temperatures for single crystal $\mathrm{Ni}_{52.6} \mathrm{Mn}_{23.1} \mathrm{Ga}_{24.3}$. The inset displays the detailed $M-H$ curves at $297 \mathrm{~K}$ and $310 \mathrm{~K}^{[12]}$

Note that the martensitic transition temperature, $T_{\mathrm{M}} \sim$ $197 \mathrm{~K}$, of $\mathrm{Ni}_{51.5} \mathrm{Mn}_{22.7} \mathrm{Ga}_{25.8}$ polycrystalline is still far below the room temperature. A general rule based on $\mathrm{NiMnZ}$ ( $Z=\mathrm{Sn}, \mathrm{In}, \mathrm{Al}, \mathrm{Ga}$ ) ternary alloys shows that $T_{\mathrm{M}}$ sharply decreases while $T_{\mathrm{C}}$ of the parent phase remains nearly unchanged with decreasing valence electron concentration $e / a .^{[40,41]}$ The decreasing slope of $T_{\mathrm{M}}$ with $e / a$ varies depending on the specific $Z$ element in NiMnZ. In another our work, ${ }^{[12]} T_{\mathrm{M}}$ was successfully tuned to room temperature through adjusting the $\mathrm{Ni}: \mathrm{Mn}: \mathrm{Ga}$ ratio to change $e / a$, and a large negative entropy change was observed in single crystal $\mathrm{Ni}_{52.6} \mathrm{Mn}_{23.1} \mathrm{Ga}_{24.3}$. Figure 4 displays the isothermal $M-H$ curves measured at different temperatures with a magnetic field along the [001] direction of the martensitic state. Due to a reason similar to that in the case of polycrystalline $\mathrm{Ni}_{51.5} \mathrm{Mn}_{22.7} \mathrm{Ga}_{25.8}$, a cross point in the $M-H$ curve also appears as expected, which is located at a lower magnetic field of $0.23 \mathrm{~T}$. This means that the transition from the martensitic state to the austenitic state brings an increase of magnetization below $0.23 \mathrm{~T}$ but a decrease of magnetization above $0.23 \mathrm{~T}$. It is clear, from Maxwell's relations, that the integral value of $\Delta S$ is positive below $0.23 \mathrm{~T}$. When the applied field reaches $0.45 \mathrm{~T}$, the positive $\Delta S$ is offset, and further increasing the field above $0.45 \mathrm{~T}$ results in net negative
$\Delta S$. The interesting behavior of $\Delta S$ should be ascribed to the fundamental magnetic properties of the sample.

Figure 5 shows $\Delta S$ as a function of temperature under different applied fields. Note that the $\Delta S$ under a field above $0.45 \mathrm{~T}$ is negative and two peaks appear. The higher one is located at $300 \mathrm{~K}$, and the maximal value under $5 \mathrm{~T}$ reaches $18.0 \mathrm{~J} \cdot \mathrm{kg}^{-1} \cdot \mathrm{K}^{-1}$. This value is roughly comparable with that of $\mathrm{Gd}_{5} \mathrm{Si}_{2} \mathrm{Ge}_{2}{ }^{[5]}$ and notably exceeds that of $\mathrm{Gd}^{[42,43]}$ near room temperature. The two $\Delta S$ peaks are attributed to the coexistence of two crystallographic phases in one sample. It is known that the structural transition temperature of the Ni-Mn-Ga system is very sensitive to its composition, and a grown single crystal usually has a small variation in composition due to the preparation technique. Although the measured sample cut from the single-crystal boule is small, $\sim 13.53 \mathrm{mg}$ in weight, two phases with a small difference of composition may coexist, resulting in two adjacent transitions. From Fig. 4, one can also find that with increasing temperature, two abrupt decreases of magnetization occur in the $M-H$ curves. The scope of the first decrease, from $300 \mathrm{~K}$ to $302 \mathrm{~K}$, is $7.5 \mathrm{~A} \cdot \mathrm{m}^{2} \cdot \mathrm{kg}^{-1}$, and that of the second, from $303 \mathrm{~K}$ to $305 \mathrm{~K}$, is $2.35 \mathrm{~A} \cdot \mathrm{m}^{2} \cdot \mathrm{kg}^{-1}$, resulting in the two $\Delta S$ peaks with different heights. It is easy to understand that the proportion of the two phases directly influences the scope of the decreased magnetization and, further, the heights of the two $\Delta S$ peaks. This fact also tells us that the large magnitude of $\Delta S$ and the wide temperature span may be achieved by controlling the composition distribution through controlling the process of single-crystal growth. Usually, the saturated magnetization of low-temperature martensite is higher than that of high-temperature austenite by $10-20 \% .^{[44,45]}$ For the present sample, due to the possibility of two-phase coexistence, two abrupt decreases of magnetization take place with increasing temperature. The combined result makes the saturated magnetization of the martensitic state at low temperature $297 \mathrm{~K}$ $45 \%$ higher than that of the austenitic state at high temperature $310 \mathrm{~K}$ for single crystal $\mathrm{Ni}_{52.6} \mathrm{Mn}_{23.1} \mathrm{Ga}_{24.3}$.

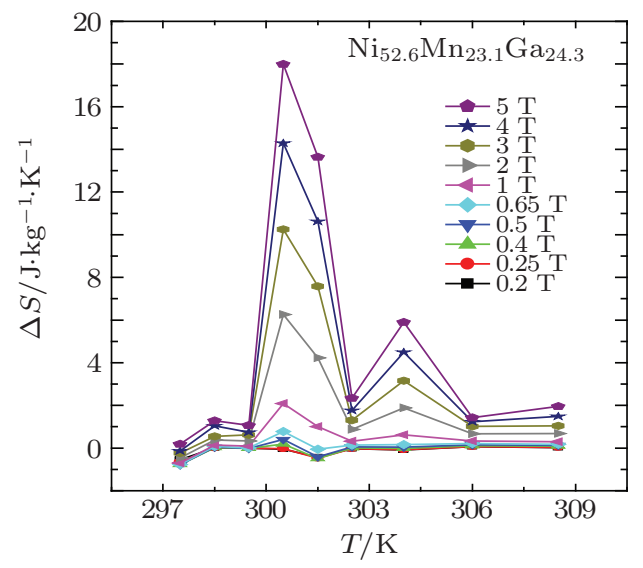

Fig. 5. Magnetic entropy change as a function of temperature under different applied fields along the [001] direction for single crystal $\mathrm{Ni}_{52.6} \mathrm{Mn}_{23.1} \mathrm{Ga}_{24.3} .^{[12]}$ 
The magnetocrystalline anisotropy of martensite varies depending on the structure and the composition, leading to a variation of the crossing point in the $M-H$ curves of martensite and austenite. In another single crystal sample $\mathrm{Ni}_{50.1} \mathrm{Mn}_{20.7} \mathrm{Ga}_{29.6}$ with the crossing point at $\sim 0.8 \mathrm{~T}$ and $T_{\mathrm{M}}$ at $\sim 214 \mathrm{~K}, \mathrm{we}^{[46]}$ observed interesting positive and negative behaviors of $\Delta S$ (Fig. 6) due to a similar reason related to the magnetic anisotropy. The peak value of positive $\Delta S$ increases with increasing applied field until it reaches an extreme value about $\sim 6.0 \mathrm{~J} \cdot \mathrm{kg}^{-1} \cdot \mathrm{K}^{-1}$ at $0.8 \mathrm{~T}$, while above $0.8 \mathrm{~T}$, an increase of the applied field results in a decrease of $\Delta S$. When the field reaches $5 \mathrm{~T}$, the negative $\Delta S$ exhibits a maximal magnitude of about $\sim 6.0 \mathrm{~J} \cdot \mathrm{kg}^{-1} \cdot \mathrm{K}^{-1}$ at $\sim 219 \mathrm{~K}$. One can also note that a small positive peak appears adjacent to the valley when the field exceeds $0.8 \mathrm{~T}$, which can be ascribed to the coexistence of the martensitic and the austenitic phases near the transition temperature. When the transformation process from the martensitic phase to the austenitic phase is nearly complete, the influence of the residual martensitic phase on the anisotropy field seems stronger than that on the magnetization, which causes the positive entropy change. It is evident that the $\mathrm{Ni}_{50.1} \mathrm{Mn}_{20.7} \mathrm{Ga}_{29.6}$ single crystal shows obvious superiority under low fields. The magnitude of positive $\Delta S$ is $\sim 6.0 \mathrm{~J} \cdot \mathrm{kg}^{-1} \cdot \mathrm{K}^{-1}$ under a low field of $0.8 \mathrm{~T}$.

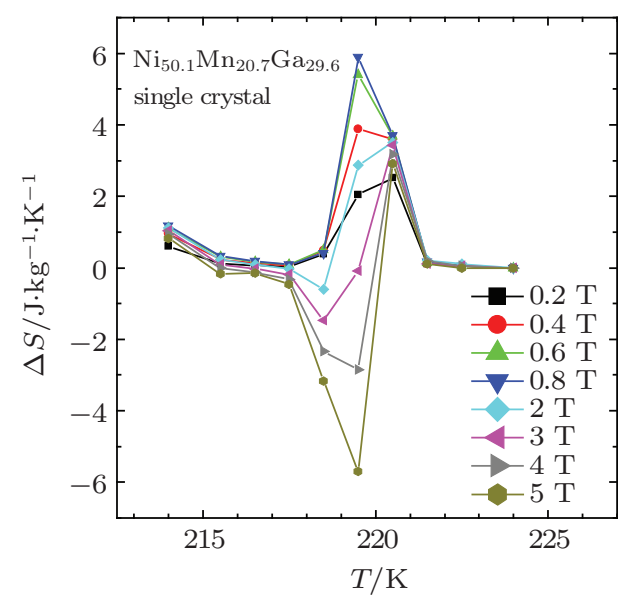

Fig. 6. Magnetic entropy change $\Delta S$ as a function of temperature under different applied fields along the [001] direction for single crystal $\mathrm{Ni}_{50.1} \mathrm{Mn}_{20.7} \mathrm{Ga}_{29.6} \cdot{ }^{[46]}$

Many investigations have focused on the MCE and the related mechanism for the conventional Heusler alloys $\mathrm{Ni}-$ $\mathrm{Mn}-Z$ ( $Z=\mathrm{Sn}, \mathrm{In}, \mathrm{Sb}, \mathrm{In})$, and a large magnitude of $\Delta S$ was observed in many compositions. ${ }^{[1-3,16]}$ Typically, through adjusting the ratio of Ni:Mn:Z, one can overlap the two transitions of martensitic structure and the FM-PM transitions, and an enhanced magnitude of $\Delta S$ as high as $\sim 86 \mathrm{~J} \cdot \mathrm{kg}^{-1} \cdot \mathrm{K}^{-1}$ can be obtained. ${ }^{[27]}$

\section{Magnetocaloric effect in metamagnetic NiMn-based Heusler alloys with rich Mn con- tent}

For the conventional Ni-Mn-Z Heusler alloys, both martensite and austenite display strong FM properties. The large $\Delta S$ is associated with the martensitic structural transformation and the magnetic anisotropy in martensite. Although the magnitude of $\Delta S$ can be very large, $\Delta S$ is usually concentrated in a narrow temperature range, $\sim 1-5 \mathrm{~K}$. The difference of saturated magnetization across the martensitic transformation is small, and the resulting Zeeman energy $\mu_{0} \Delta M \cdot H$ cannot be large enough to drive a large shift of the martensitic temperature, thus a narrow temperature span of large $\Delta S$ appears. It is well known that a real magnetic refrigerator requires not only a large MCE but also a wide temperature span. The narrow temperature span of $\Delta S$ for the conventional NiMn-based Heusler alloys may hinder the practical use of these alloys.

The recent discovery of metamagnetic shape memory alloys (MSMAs) has stirred intense interest because of their huge shape memory effect and some mechanisms differing from those of the conventional alloys. ${ }^{[47,48]}$ In these Ga-free $\mathrm{Ni}-\mathrm{Mn}-Z$ Heusler alloys, where $Z$ can be a group III or IV element such as In, Sn, or Sb, the excess of Mn causes a fundamental change of magnetism between the parent and the product phases. As the Mn content exceeds the ratio 2:1:1 in $\mathrm{Ni}: \mathrm{Mn}: Z$, the nearest Mn-Mn neighbors are introduced, which usually gives rise to antiferromagnetic (AFM) coupling. As a result, a considerable large difference of saturated magnetization across the martensitic transformation appears, and the resulting Zeeman energy $\mu_{0} \Delta M \cdot H$ can be large enough to drive a structural transformation and cause the field-induced metamagnetic behavior, which is responsible for the huge shape memory effect. Furthermore, it has been found that the incorporation of Co atoms can be an "FM activator"[49,50] and enlarge the magnetization difference across the martensitic transformation; hence an extremely large stress can be generated by a magnetic field. ${ }^{[47]}$ It has been reported that the stress output for the composition of $\mathrm{Ni}_{45} \mathrm{Co}_{5} \mathrm{Mn}_{36.6} \mathrm{In}_{13.4}$ can be over $100 \mathrm{MPa}$ under a $7 \mathrm{~T}$ field, ${ }^{[47]}$ which is approximately 50 times larger than that in the conventional Heusler alloys. The simultaneous changes in the structural and magnetic properties induced by the magnetic field should be accompanied by a large MCE in an extended temperature range.

Many groups have studied the crystal structure, magnetic properties, MCE, and magnetoresistance (MR) behavior in novel metamagnetic alloys. An MR as large as $-80 \%$ under a field change of $0-5 \mathrm{~T}$ has been reported. ${ }^{[51-56]}$ Since the low temperature martensite shows weak magnetization compared to the parent phase, an inverse MCE occurs, which can be easily understood from Maxwell's relations. In 2005, 
an inverse $\Delta S$ as large as $18.5 \mathrm{~J} \cdot \mathrm{kg}^{-1} \cdot \mathrm{K}^{-1}$ at about $300 \mathrm{~K}$ under a field change of 0-5 $\mathrm{T}$ was reported in a polycrystalline alloy $\mathrm{Ni}_{50} \mathrm{Mn}_{37} \mathrm{Sn}_{13} \cdot{ }^{[13]}$ Later, many scientists devoted their attention to the MCE involving metamagnetic behavior in the alloys. ${ }^{[14-16,29-33,53,54,56-68]}$ A large inverse $\Delta S$ was reported in a number of compositions with rich Mn concentration, such as $\mathrm{Ni}_{45.4} \mathrm{Mn}_{41.5} \mathrm{In}_{13.1},{ }^{[30]} \mathrm{Ni}_{50-x} \mathrm{Mn}_{39+x} \mathrm{Sn}_{11},{ }^{[32]}$ $\mathrm{Ni}_{43} \mathrm{Mn}_{46} \mathrm{Sn}_{11} \mathrm{~B}_{x},{ }^{[57]} \mathrm{Ni}_{50} \mathrm{Mn}_{50-x} \mathrm{Sb}_{x},{ }^{[58]} \mathrm{Ni}_{51} \mathrm{Mn}_{49-x} \mathrm{In}_{x} \mathrm{H}_{\delta}$, ${ }^{[59]}$ and $\mathrm{Ni}_{45}\left(\mathrm{Co}_{1-x} \mathrm{Fe}_{x}\right)_{5} \mathrm{Mn}_{36.6} \mathrm{In}_{13.4 .}{ }^{[53]}$ Along with the concurrent metamagnetic and structural transitions, a large barocaloric effect has also been reported. ${ }^{[14]}$ Ribbons have also been prepared by the melting-spun technique, ${ }^{[54,60-62]}$ and the effects of annealing on the martensitic transformation and the MCE have been studied. ${ }^{[55,63,69,70]}$ Furthermore, Li et al. investigated the magnetostructural coupling in $\mathrm{Ni}_{50} \mathrm{Mn}_{35} \mathrm{In}_{15}$ systems and identified the contribution of the lattice-entropy change to the total entropy change. ${ }^{[64]}$ Very recently, Liu et al. demonstrated that the structural transition plays a dominant role for the considerable adiabatic temperature change in the metamagnetic NiMnCoIn alloys. ${ }^{[15]}$

Here we mainly review our recent progress with regard to the effects of atomic substitution, post-annealing, the introduction of interstitial atoms, and forced atomic disorder on the magnetic, magnetocaloric, and transport properties of the novel NiMn-based metamagnetic Heusler alloys.

\subsection{Tuning magnetic entropy change of $\mathbf{N i}_{50-x} \mathbf{M n}_{35+x} \mathbf{I n}_{15}$ alloys by varying Mn content}

A detailed investigation of $\mathrm{Ni}_{50} \mathrm{Mn}_{50-y} \mathrm{In}_{y}$ alloys ${ }^{[41]}$ indicated that the composition with $y=16$ is the only one that exhibits a field-induced structural transition in this series of alloys. Although the compositions with In content of $y=15.5$ and 15 undergo a martensitic transformation, an external field cannot shift the transition temperature because of the low Zeeman energy $\mu_{0} \Delta M \cdot H$, which leads to a narrow temperature span for the MCE. In contrast, a strong shift of the martensitic transition toward lower temperatures can be driven by a magnetic field for the sample with $y=16$. Several groups investigated its shape memory effect and MCE. The reported inverse $\Delta S$ with a considerable temperature span reaches $12 \mathrm{~J} \cdot \mathrm{kg}^{-1} \cdot \mathrm{K}^{-1}$ under a field change of $0-5 \mathrm{~T},{ }^{[71]}$ which is larger than that of Gd. However, the large $\Delta S$ occurs around $180 \mathrm{~K}$, still far below the room temperature. $\mathrm{We}^{[65]}$ chose $\mathrm{Ni}_{50-x} \mathrm{Mn}_{35+x} \mathrm{In}_{15}$ and studied its structure, magnetic properties, and MCE. By changing the Mn content but fixing the In content, a field-induced structural transition was realized in a modified composition, with $T_{\mathrm{M}}$ at $285 \mathrm{~K}$. Associated with the field-induced metamagnetic behavior, a huge $\Delta S$ with a wide temperature span was observed near room temperature.

Figure 7 shows the temperature dependent zero-field cooling (ZFC) and field cooling (FC) magnetizations ${ }^{[65]}$ under $0.05 \mathrm{~T}$ for samples of $x=0,3,4$. For the $x=0$ sample, the magnetization gradually increases on cooling, and the appearance of a small cusp indicates the onset of the FM order of the austenitic phase. However, before the FM transition in the austenitic phase is completed, the martensitic transformation has already taken place at $T_{\mathrm{M}} \sim 314 \mathrm{~K}$ with a hysteresis about $8 \mathrm{~K}$. Continuously reducing the temperature leads to the FM ordering of the martensitic phase with Curie temperature $T_{\mathrm{C}}^{\mathrm{M}} \sim 170 \mathrm{~K}$. At temperatures lower than $135 \mathrm{~K}$, a large separation between ZFC and FC magnetizations is observed, which is understandable considering the magnetic anisotropy in the martensitic state and the existence of both FM and AFM clusters. ${ }^{[41]}$

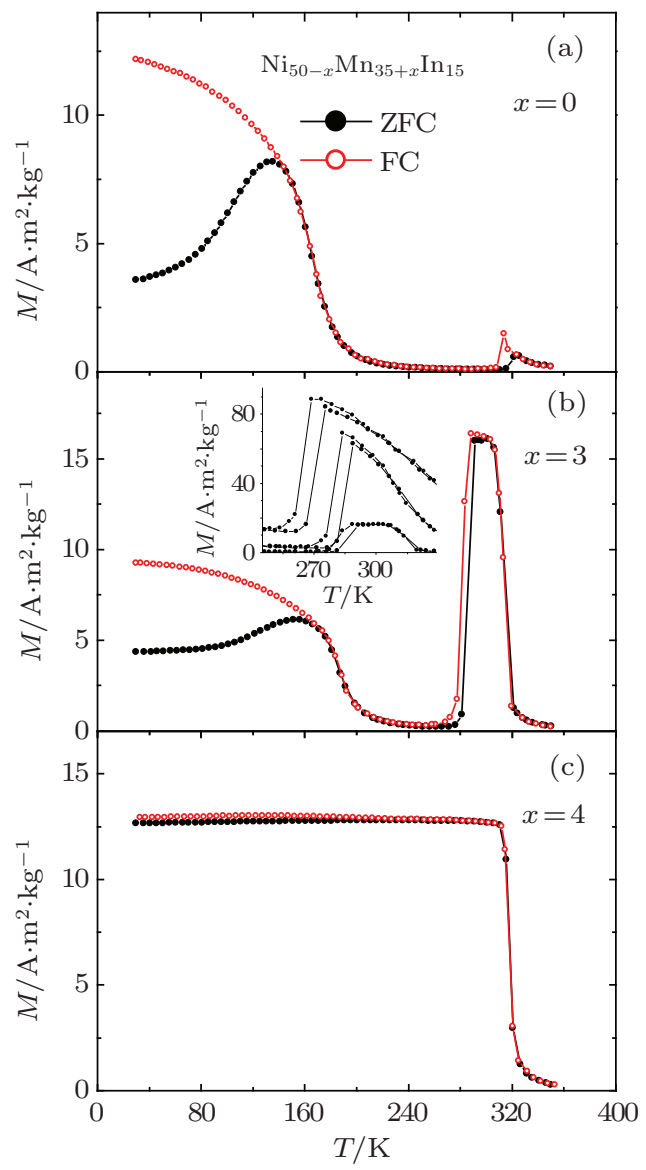

Fig. 7. Temperature dependent $\mathrm{ZFC}$ and FC magnetizations measured under a $0.05 \mathrm{~T}$ magnetic field for $\mathrm{Ni}_{50-x} \mathrm{Mn}_{35+x} \mathrm{In}_{15}$ alloys with (a) $x=0$, (b) $x=3$, (c) $x=4$. The inset of panel (b) shows the ZFC-ZC magnetizations measured under different fields of $0.05 \mathrm{~T}, 1 \mathrm{~T}$, and $5 \mathrm{~T}$ for the sample with $x=3$. $^{[65]}$

With increasing $\mathrm{Mn}$ content, $T_{\mathrm{M}}$ decreases but $T_{\mathrm{C}}^{\mathrm{M}}$ increases, which is in accord with the general dependence of the transition temperatures on the valence electron concentration in NiMn-based alloys. ${ }^{[40,41]}$ The inset of Fig. 7(b) shows the temperature dependent magnetizations measured under different fields of $0.05 \mathrm{~T}, 1 \mathrm{~T}$, and $5 \mathrm{~T}$ for the $x=3$ sample. In contrast to $x=0, T_{\mathrm{M}}$ can be shifted to lower temperature at a rate of $3.5 \mathrm{~K} / \mathrm{T}$ upon the application of magnetic field, and a field-induced metamagnetic transition takes place, similar 
to the case in the $\mathrm{Ni}_{50} \mathrm{Mn}_{34} \mathrm{In}_{16}$ alloy; thus a large entropy change in a broadening temperature range can be expected. Figure 8 displays $\Delta S$ versus temperature under different magnetic fields, calculated based on Maxwell's relations, ${ }^{[1-3]}$ for the $x=3$ sample. One can find that the inverse $\Delta S$ is located near room temperature. With increasing magnetic field, the $\Delta S$ peak gradually expands toward lower temperatures because of the field-induced metamagnetic transition behavior, and a wide span of $\Delta S$ appears. The maximal effective $\Delta S$ (the high plateau, not the spike ${ }^{[72,73]}$ ) is about $21 \mathrm{~J} \cdot \mathrm{kg}^{-1} \cdot \mathrm{K}^{-1}$ near $T_{\mathrm{C}}^{\mathrm{M}} \sim 285 \mathrm{~K}$, and the temperature span of $\Delta S$ reaches $15 \mathrm{~K}$ under a field change of $0-5 \mathrm{~T}$. This $\Delta S$ is much larger than that of the traditional refrigerant $\mathrm{Gd}^{[42,43]}$

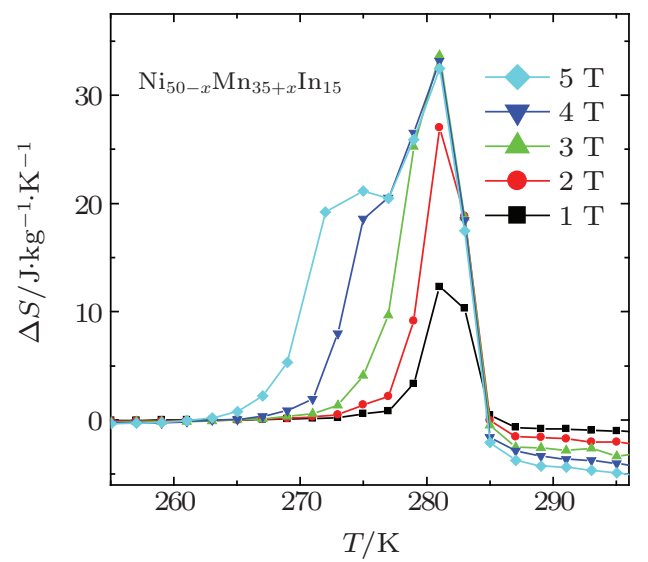

Fig. 8. Magnetic entropy change $\Delta S$ as a function of temperature at different magnetic fields for $\mathrm{Ni}_{50-x} \mathrm{Mn}_{35+x} \operatorname{In}_{15}(x=3)$ alloy. ${ }^{[65]}$

\subsection{Magnetocaloric effect and magnetoresistance in Co- doped metamagnetic alloys}

The huge FM shape memory effect recently discovered in metamagnetic alloys with exact compositions $\mathrm{Ni}_{45} \mathrm{Co}_{5} \mathrm{Mn}_{50-x} \mathrm{In}_{x}(x=13.3,13.4,13.5)^{[47,48]}$ warrants further experimental and theoretical study. The introduction of Co atoms in metamagnetic alloys enhances the Zeeman energy $\mu_{0} \Delta M \cdot H$ through enlarging the magnetization difference across the martensitic transformation; thus an extremely large stress can be generated by a magnetic field. The simultaneous changes in the structure and magnetic properties induced by a magnetic field must be accompanied by a large MCE. The concurrent changes in the electronic structure and the scattering mechanisms across the martensitic transformation must also alter the transport properties. Naturally, a large MCE and a distinct MR effect can be expected along with the fieldinduced structural transformation.

Chen et al. ${ }^{[56]}$ prepared $\mathrm{Ni}_{45} \mathrm{Co}_{5} \mathrm{Mn}_{36.5} \mathrm{In}_{13.5}$ polycrystalline alloys by an arc-melting technique and studied the MCE and the MR effect. The temperature dependent ZFCFC magnetizations ${ }^{[65]}$ measured under $0.05 \mathrm{~T}, 1 \mathrm{~T}$, and $5 \mathrm{~T}$ indicates that the martensitic temperature $T_{\mathrm{M}}$ locates at $260 \mathrm{~K}$ and $214 \mathrm{~K}$ under magnetic fields $0.05 \mathrm{~T}$ and $5 \mathrm{~T}$, respectively.
It is clear that a decrease of about $46 \mathrm{~K}$ is driven by an external magnetic field of $5 \mathrm{~T}$. The equated driving rate of $T_{\mathrm{M}}$ is $\sim 9.2 \mathrm{~K} / \mathrm{T}$, one time higher than that of $\mathrm{Ni}_{45} \mathrm{Co}_{5} \mathrm{Mn}_{36.6} \mathrm{In}_{13.4}$ reported in Ref. [47]. This means that the martensitic transformation in the present $\mathrm{Ni}_{45} \mathrm{Co}_{5} \mathrm{Mn}_{36.5} \mathrm{In}_{13.5}$ is easier to drive by a magnetic field. It is also found that the thermal hysteresis around $T_{\mathrm{M}}$ enlarges from $\sim 10 \mathrm{~K}$ to $\sim 32 \mathrm{~K}$ when the magnetic field increases from $0.05 \mathrm{~T}$ to $5 \mathrm{~T}$. The hysteresis behavior is commonly believed to be related to the nucleation of a new phase and the interfacial interaction at the phase boundary in first-order systems. The previous investigations indicate that the hysteresis gap can characterize the friction strength of phase boundary motions during the martensitic transformation in Heusler alloys. ${ }^{[74]}$ The enhancement of hysteresis may imply that the friction resisting the transformation becomes larger with increasing magnetic field.

Figures 9(a) and 9(b) display the temperature dependent resistance $(R-T$ curves) under $0 \mathrm{~T}$ and $5 \mathrm{~T}$, and the field dependent resistance up to $5 \mathrm{~T}$ at different temperatures for $\mathrm{Ni}_{45} \mathrm{Co}_{5} \mathrm{Mn}_{36.5} \mathrm{In}_{13.5}$ polycrystalline. An abrupt increase in resistance appears as the sample undergoes the martensitic transformation. An enlarged thermal hysteresis with increasing field can also be identified from the $R-T$ curves, consistent with the results of the thermomagnetization measurements. With $T_{\mathrm{M}}$ shifting to a lower temperature under an external field, a negative MR was observed. Figure 9(c) plots the deduced field dependent MR at various temperatures around $T_{\mathrm{M}}$. One can note that the maximal MR under $5 \mathrm{~T}$ exceeds $80 \%$ around $235 \mathrm{~K}$. At temperatures near $T_{\mathrm{M}}$, a low field can induce a metamagnetic transition, thus generating a considerable large MR. For example, at $250 \mathrm{~K}$, a field of $2.5 \mathrm{~T}$ can produce an MR as large as $60 \%$. Importantly, the transport resistance is fully recoverable against the magnetic field. It can return to its original value after a field cycle. As the sample experiences the martensitic transformation, the increased interfacial scattering at the twin boundaries and the change of lattice symmetry may enhance resistivity due to the electron-phonon scattering. Moreover, the concurrent alteration of magnetic properties may also contribute to a change in resistivity due to the electron-spin scattering. In metamagnetic Heusler alloys, the austenitic state usually exhibits strong FM properties while the martensitic state shows a small magnetization. A recent neutron polarization analysis experiment ${ }^{[75]}$ observed AFM correlations at temperatures below $T_{M}$ for some Mn-rich alloys with metamagnetic properties. Similar to the materials that undergo AFM transition, ${ }^{[76]}$ the formation of superzone boundary gaps may alter the density of the electronic states near the Fermi surface, leading to an enhancement of transport resistance due to the electron-spin scattering. 

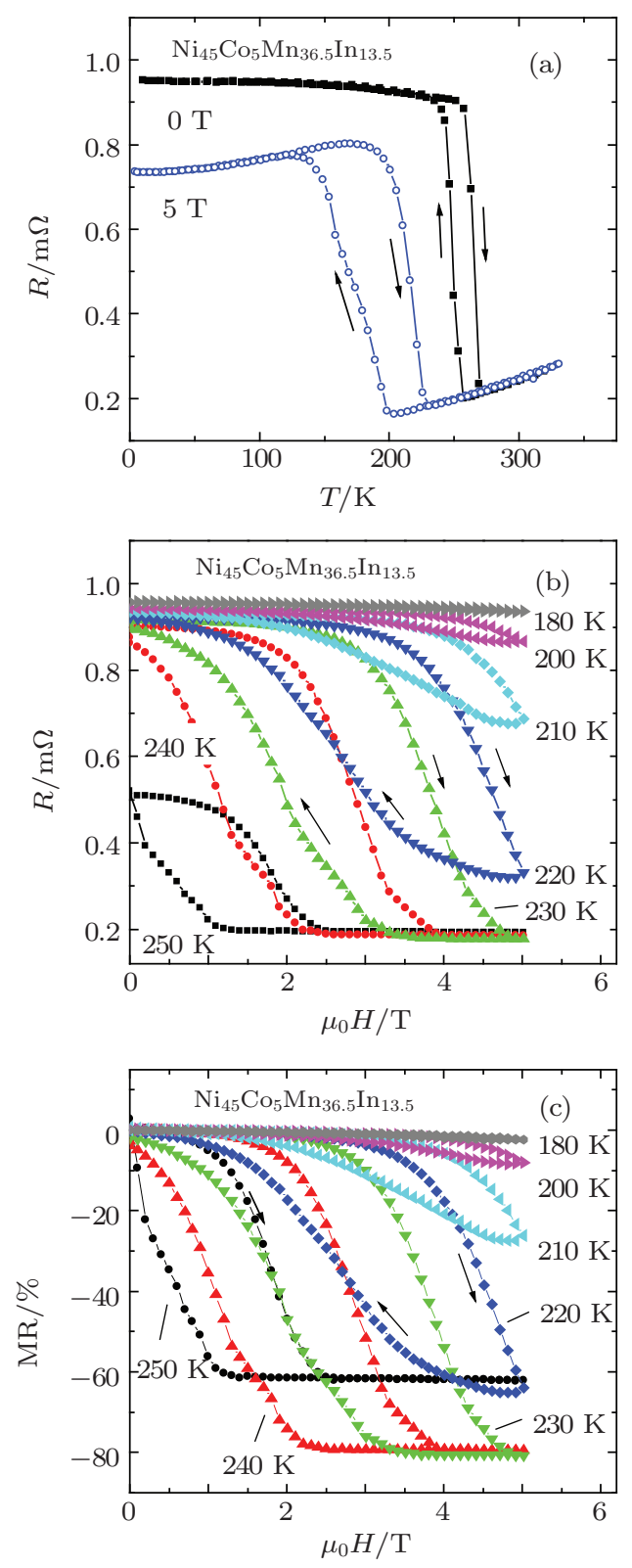

Fig. 9. (a) Temperature dependent resistance under $0 \mathrm{~T}\left(R_{0 \mathrm{~T}}\right)$ and $5 \mathrm{~T}$ $\left(R_{5 \mathrm{~T}}\right)$, (b) field dependent resistance up to $5 \mathrm{~T}$ at different temperatures, and (c) field dependent $\mathrm{MR}\left[\left(R_{5 \mathrm{~T}}-R_{0 \mathrm{~T}}\right) / R_{0 \mathrm{~T}}\right]$ at different temperatures for $\mathrm{Ni}_{45} \mathrm{Co}_{5} \mathrm{Mn}_{36.5} \mathrm{In}_{13.5}$. The arrows indicate the heating/cooling paths as well as the field ascending/descending paths. ${ }^{[56]}$

Magnetization measurements as functions of temperature and magnetic field were carried out, and $\Delta S$ was calculated using Maxwell's relation. ${ }^{[1-3]}$ The maximal $\Delta S$ is about $\sim 22 \mathrm{~J} \cdot \mathrm{kg}^{-1} \cdot \mathrm{K}^{-1}$ at $\sim 252 \mathrm{~K}$ under a field change of $0-5 \mathrm{~T}$. This value roughly agrees with the $\Delta S$ ( $\sim 27 \mathrm{~J} \cdot \mathrm{kg}^{-1} \cdot \mathrm{K}^{-1}, 7 \mathrm{~T}$ ) obtained by using the ClausiusClapeyron relation and the DSC measurements for a close composition $\mathrm{Ni}_{45} \mathrm{Co}_{5} \mathrm{Mn}_{36.6} \mathrm{In}_{13.4} \cdot{ }^{[4]}$

Similarly, Gao et al. ${ }^{[68]}$ investigated the MCE associated with metamagnetic properties in another Co-doped composition $\mathrm{Ni}_{43} \mathrm{Mn}_{43} \mathrm{Co}_{3} \mathrm{Sn}_{11}$. The $\Delta S$ peak gradually develops into a high plateau with increasing magnetic field. The $\Delta S$ value is about $\sim 33 \mathrm{~J} \cdot \mathrm{kg}^{-1} \cdot \mathrm{K}^{-1}$ under a field change of $0-5 \mathrm{~T}$. The differing $\Delta S$ magnitudes in different systems must be related to the fundamental difference of magnetic properties and the different latent heat of phase transitions.

\subsection{Large magnetic entropy change with small thermal hysteresis in metamagnetic alloys $\mathbf{N i}_{51} \mathbf{M n}_{49-x} \mathbf{I n}_{x}$}

NiMn-based metamagnetic Heusler alloys have attracted lots of attention due to their unusual multi-functional properties. However, a large hysteresis is usually accompanied by a metamagnetic behavior due to the first-order nature of the transition. The reported thermal hysteresis can be as large as $\sim 20 \mathrm{~K}$ for $\mathrm{Ni}-\mathrm{Mn}-\mathrm{Sn}^{[32]}$ and $\sim 10 \mathrm{~K}$ for $\mathrm{Ni}-\mathrm{Co}-\mathrm{Mn}-$ $\mathrm{In}^{[47]}$ alloys. For $\mathrm{Ni}_{50} \mathrm{Mn}_{34} \mathrm{In}_{16}$, the hysteresis even reaches $20 \mathrm{~K}$, and more importantly, it becomes wider with an external field. ${ }^{[71]}$ As discussed above, the composition $\mathrm{Ni}_{50} \mathrm{Mn}_{34} \mathrm{In}_{16}$ is the only one that exhibits a field-induced transition in $\mathrm{Ni}_{50} \mathrm{Mn}_{50-y} \mathrm{In}_{y}$ alloys. ${ }^{[41]}$ We tuned compositions around the ratio $\mathrm{Ni}_{50} \mathrm{Mn}_{34} \mathrm{In}_{16}$ and were surprised to observe a small thermal hysteresis $(<2 \mathrm{~K})$ in $\mathrm{Ni}_{51} \mathrm{Mn}_{49-x} \mathrm{In}_{x}(x=15.6,16.0$, 16.2). ${ }^{[66]}$ It was found that a little more increase of Ni content not only increases $T_{\mathrm{M}}$ but also enhances the $\Delta S$. More importantly, it can remarkably reduce the thermal hysteresis.

Figure 10 displays the temperature dependent $\mathrm{ZFC}$ and FC magnetizations ${ }^{[65]}$ measured under different fields for polycrystalline $\mathrm{Ni}_{51} \mathrm{Mn}_{49-x} \mathrm{In}_{x}(x=15.6,16.0,16.2)$. Note that the martensitic temperature $T_{\mathrm{M}}$ decreases monotonously from $308 \mathrm{~K}$ to $253 \mathrm{~K}$ with In content $x$ varying from 15.6 to 16.2. Due to the metamagnetic characteristics across the martensitic transformation, an external magnetic field can shift $T_{\mathrm{M}}$ to lower temperatures, but the driving rate is different for different compositions. Compared to the composition with $x=$ 15.6, the martensitic transformation of the other two ( $x=16.0$, $16.2)$ is easier to drive, and thus a wider temperature span of $\Delta S$ is expected.

From Fig. 10, one can also find that the $\mathrm{Ni}_{51} \mathrm{Mn}_{49-x} \mathrm{In}_{x}$ alloys show a very small thermal hysteresis $(<2 \mathrm{~K})$ around $T_{\mathrm{M}}$. More importantly, an increase in magnetic field does not enlarge the hysteresis for all samples. The previous investigations ${ }^{[74,77,78]}$ indicate that the hysteresis effect is a complicated issue in thermoelastic martensitic transformation systems. The dissipative mechanisms for hysteresis are different at different spatial scales. ${ }^{[78]}$ At the microscopic scale, the hysteresis is related to the nucleation of a new phase and the interaction of interfaces with defects. But at the mesoscopic scale, the hysteresis effect comes from the formation, annihilation, and rearrangement of elastically interacting domains. In this case, the heat transfer within the alloy and that with the surroundings also affect the hysteresis gap. Considering the small size of the measured samples, $50-85 \mathrm{~g},{ }^{[66]}$ the heat transfer should be good during the magnetic measurements. The frictions from both domain rearrangements and phase boundary motions are considered to be a key factor affecting the 
hysteresis gap. ${ }^{[74,77]}$ In other words, the gap of the thermal hysteresis may characterize the strength of frictions during the transformation. The small hysteresis indicates that the friction to resist the transformation with temperature is small.

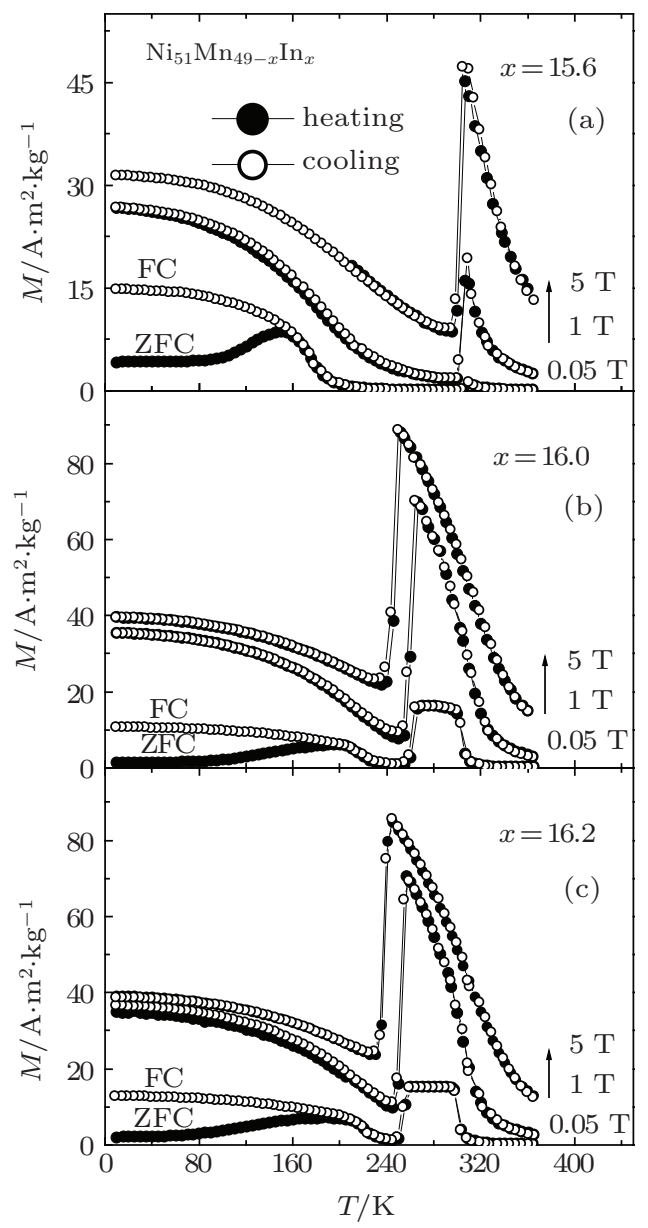

Fig. 10. Temperature dependent $\mathrm{ZFC}$ and FC magnetizations measured under different fields $0.05 \mathrm{~T}, 1 \mathrm{~T}$, and $5 \mathrm{~T}$ for $\mathrm{Ni}_{51} \mathrm{Mn}_{49-x} \mathrm{In}_{x}$ ((a) $x=15.6$, (b) $x=16.0$, (c) $x=16.2$ ) alloys. ${ }^{[66]}$

However, unlike the behavior in a temperature cycle, the isothermal $M-H$ curves measured around $T_{\mathrm{M}}$ show a large magnetic hysteresis in field cycles. The area enclosed in a field cycle at $258 \mathrm{~K}$ can be as large as $\sim 77 \mathrm{~J} / \mathrm{kg}$. For most first-order systems, the thermal and the magnetic hystereses usually occur synchronously. The differing hysteresis behaviors in temperature and field cycles may indicate that nucleation mechanisms differ under different external perturbations, which may correlate not only with the composition but also the microstructure. For details, further investigations are still required.

Figure 11 shows the $\Delta S$ as a function of temperature and magnetic field calculated based on Maxwell's relations. ${ }^{[1-3]}$ Note that the inverse $\Delta S$ peaks at $T_{\mathrm{M}}$ and gradually broadens toward lower temperatures. The maximal $\Delta S$ is $33 \mathrm{~J} \cdot \mathrm{kg}^{-1} \cdot \mathrm{K}^{-1}, 20 \mathrm{~J} \cdot \mathrm{kg}^{-1} \cdot \mathrm{K}^{-1}$, and $19 \mathrm{~J} \cdot \mathrm{kg}^{-1} \cdot \mathrm{K}^{-1}$ at $308 \mathrm{~K}$, $262 \mathrm{~K}$, and $253 \mathrm{~K}$ under a field change of 0-5 T for compositions $x=15.6,16.0$, and 16.2, respectively. In comparison with $\Delta S \sim 12 \mathrm{~J} \cdot \mathrm{kg}^{-1} \cdot \mathrm{K}^{-1}(188 \mathrm{~K})$ for $\mathrm{Ni}_{50} \mathrm{Mn}_{34} \mathrm{In}_{16}$, not only does the $T_{\mathrm{M}}$ at which $\Delta S$ peaks go much nearer to room temperature, but also the $\Delta S$ size is remarkably enhanced. Actually, the $\Delta S$ almost reaches its maximum at $2 \mathrm{~T}$ for $x=16.0$, 16.2 and $4 \mathrm{~T}$ for $x=15.6$. Further increasing the magnetic field contributes little to the magnitude but remarkably broadens the $\Delta S$ toward lower temperatures. The $\Delta S$ span can reach $\sim 20 \mathrm{~K}$ under a field change of $0-5 \mathrm{~T}$. The $\Delta S$ shows a tablelike peak under a field change of $0-5 \mathrm{~T}$ for all samples. Detailed studies have verified that the flat plateau of $\Delta S$ reflects the intrinsic nature of $\mathrm{MCE} .^{[72]}$
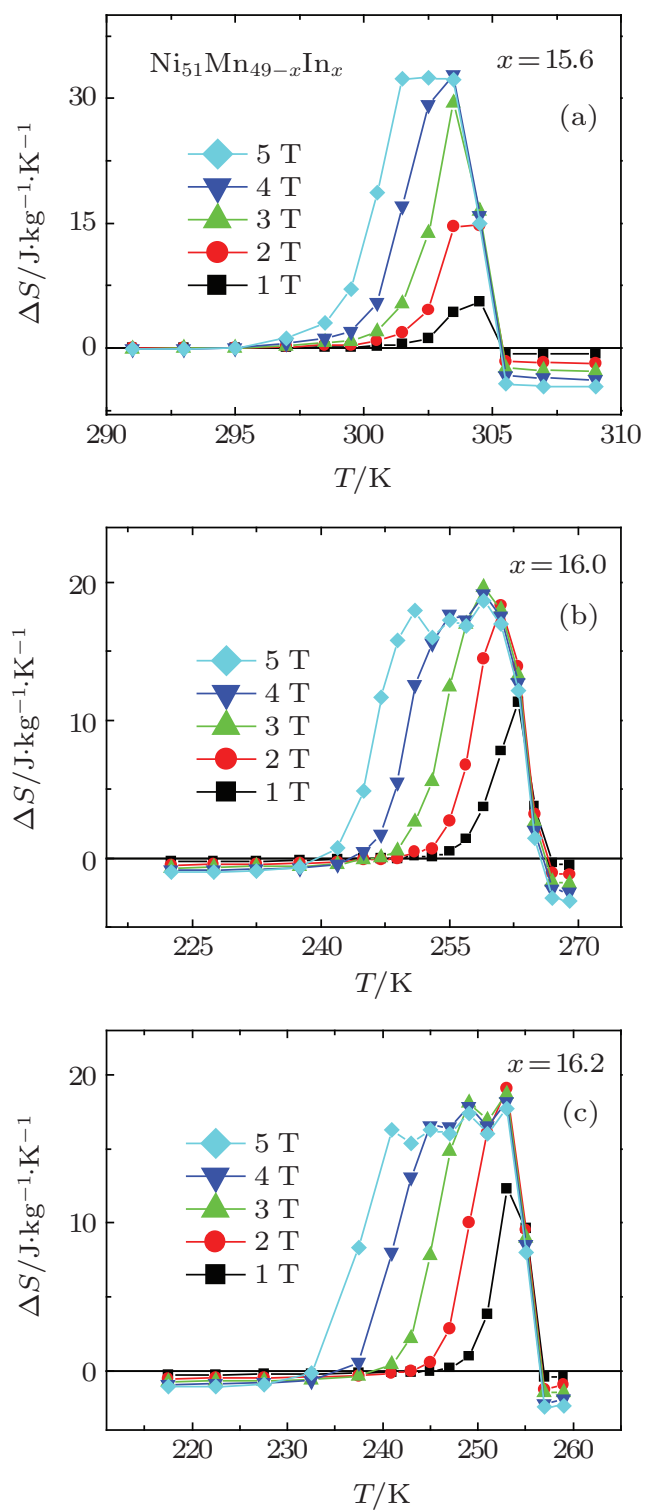

Fig. 11. Magnetic entropy change $\Delta S$ as a function of temperature and magnetic field for $\mathrm{Ni}_{51} \mathrm{Mn}_{49-x} \mathrm{In}_{x}$ ((a) $x=15.6$, (b) $x=16.0$, (c) $x=16.2$ ) alloys. ${ }^{[66]}$

\subsection{Interstitial effect on magnetic properties and mag- netic entropy change in metamagnetic Ni-Mn-In al- loys}

The metamagnetic behavior and the martensitic transformation are very sensitive to the atomic distances and the chem- 
ical surroundings. The interstitial effect is expected to influence the properties through disturbing the atomic distances and the surroundings, which may provide a useful way to tune the magnetic properties and the martensitic transition temperature, and thus the MCE. $\mathrm{We}^{[59]}$ chose metamagnetic $\mathrm{Ni}_{51} \mathrm{Mn}_{49-x} \operatorname{In}_{x}(x=16.2,16.6)$ alloys, introduced $\mathrm{H}$ atoms, and studied the interstitial effect on the magnetic properties and the magnetic entropy change.

$\mathrm{Ni}_{51} \mathrm{Mn}_{49-x} \operatorname{In}_{x}(x=16.2,16.6)$ alloys were prepared by arc-melting technique. The hydrogen was introduced by annealing the samples under hydrogen gas atmosphere in a commercial pressure-composition-temperature ( $\mathrm{P}-\mathrm{C}-\mathrm{T})$ apparatus. By adjusting the gas pressure and annealing temperature, the hydrogen concentration can be controlled and determined. $\mathrm{X}$-ray diffraction (XRD) measurements indicated that the hydrogenated samples keep the $L 2_{1}$ structure but the lattice is enlarged. The lattice parameter of $\mathrm{Ni}_{51} \mathrm{Mn}_{32.4} \mathrm{In}_{16.6} \mathrm{H}_{5.2}$ hydrides $(0.60031 \mathrm{~nm})$ is slightly larger than that of $\mathrm{Ni}_{51} \mathrm{Mn}_{32.4} \mathrm{In}_{16.6}$ $(0.59970 \mathrm{~nm})$.

Shown in Fig. 12 are the temperature dependent ZFC and FC magnetizations ${ }^{[65]}$ measured under different fields for $\mathrm{Ni}_{51} \mathrm{Mn}_{32.4} \mathrm{In}_{16.6}$ and $\mathrm{Ni}_{51} \mathrm{Mn}_{32.4} \mathrm{In}_{16.6} \mathrm{H}_{5.2}$ samples. One can find that the thermal hysteresis around $T_{\mathrm{M}}$ for $\mathrm{Ni}_{51} \mathrm{Mn}_{32.4} \mathrm{In}_{16.6}$ is small $(<2 \mathrm{~K})$, and less than $4 \mathrm{~K}$ even under a magnetic field of $5 \mathrm{~T}$, similar to that of $\mathrm{Ni}_{51} \mathrm{Mn}_{49-x} \mathrm{In}_{x}(x=15.6,16.0$, $16.2)^{[66]}$ just discussed above. For $\mathrm{Ni}_{51} \mathrm{Mn}_{32.4} \mathrm{In}_{16.6} \mathrm{H}_{5.2}$ hydride, the temperature hysteresis becomes slightly wider, $\sim$ $5 \mathrm{~K}$ under $0.05 \mathrm{~T}$, and $\sim 10 \mathrm{~K}$ when a $5 \mathrm{~T}$ magnetic field is applied. A fascinating feature is that the insertion of $\mathrm{H}$ atoms shifts $T_{\mathrm{M}}$ to a lower temperature. For $\mathrm{Ni}_{51} \mathrm{Mn}_{32.4} \mathrm{In}_{16.6} \mathrm{H}_{5.2}$, $T_{\mathrm{M}}$ appears at $\sim 217 \mathrm{~K}$, lower than that of the mother alloy by $\sim 32 \mathrm{~K}$. Another feature is that the saturated magnetization of martensitic phases is enhanced due to the introduction of $\mathrm{H}$ atoms while that of austenitic phases remains nearly unchanged. The magnetization of $\mathrm{Ni}_{51} \mathrm{Mn}_{32.4} \mathrm{In}_{16.6} \mathrm{H}_{5.2}$ at $5 \mathrm{~K}$ is $\sim 48.4 \mathrm{~A} \cdot \mathrm{m}^{2} \cdot \mathrm{kg}^{-1}$ under $5 \mathrm{~T}$, larger than that of the mother alloy $\left(\sim 43.2 \mathrm{~A} \cdot \mathrm{m}^{2} \cdot \mathrm{kg}^{-1}\right)$ by $12 \%$. The $T_{\mathrm{M}}$ of both samples is very sensitive to the external field. A $5 \mathrm{~T}$ magnetic field shifts the $T_{\mathrm{M}}$ from $249 \mathrm{~K}$ to $228 \mathrm{~K}$ at a rate of $4.2 \mathrm{~K} / \mathrm{T}$ for $\mathrm{Ni}_{51} \mathrm{Mn}_{32.4} \mathrm{In}_{16.6}$, and from $217 \mathrm{~K}$ to $193 \mathrm{~K}$ at a rate of $4.8 \mathrm{~K} / \mathrm{T}$ for $\mathrm{Ni}_{51} \mathrm{Mn}_{32.4} \mathrm{In}_{16.6} \mathrm{H}_{5.2}$. Although the magnetization difference across the martensitic transition, $\Delta M$, is somewhat reduced by inserting $\mathrm{H}$ atoms, the driving rate shows a small increase, indicating that the insertion of $\mathrm{H}$ atoms makes the martensitic transition easier to drive under the same Zeeman energy. The previous studies ${ }^{[79]}$ show that a very small change of the Mn-Mn distance will greatly affect the magnetic properties of the sample. In $\mathrm{Ni}_{51} \mathrm{Mn}_{32.4} \mathrm{In}_{16.6}$, the authentic phase shows strong FM properties, indicating that the Mn-Mn FM exchange dominates the authentic state. A small change of the $\mathrm{Mn}-\mathrm{Mn}$ distance caused by $\mathrm{H}$ atoms may not significantly influence the FM properties; hence the $T_{\mathrm{C}}^{\mathrm{A}}$ and the saturated magnetization remain nearly unchanged upon $\mathrm{H}$ doping. However, for the martensitic state, the Mn-Mn AFM coupling will play a key role in determining the magnetic properties due to the crystalline symmetry being different from that in the authentic state. The introduction of $\mathrm{H}$ atoms elongates the $\mathrm{Mn}-$ Mn distance, making the system favor the FM coupling, thus leading to an enhancement of the saturated magnetization of the martensitic state.

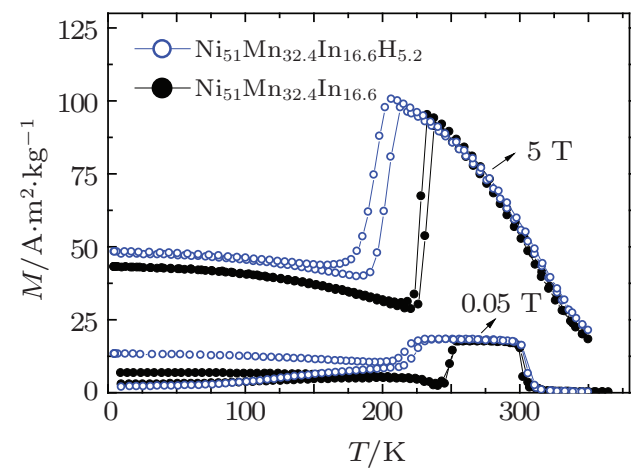

Fig. 12. Temperature dependent ZFC and FC magnetizations measured under different fields of $0.05 \mathrm{~T}$ and $5 \mathrm{~T}$ for $\mathrm{Ni}_{51} \mathrm{Mn}_{32.4} \mathrm{In}_{16.6}$ and $\mathrm{Ni}_{51} \mathrm{Mn}_{32.4} \mathrm{In}_{16.6} \mathrm{H}_{5.2}$ samples. ${ }^{[59]}$

Valence electron concentration $e / a$ is a critical factor that influences the martensitic transformation behavior and the magnetic properties. ${ }^{[40,41]}$ The addition of $\mathrm{H}$ may also affect $T_{\mathrm{M}}$ by altering $e / a$. Itsumi et al. carried out electronic structure calculations for body-centered cubic (bcc) Fe with interstitial $\mathrm{H}$ by using the first-principles discrete variational method. ${ }^{[80]}$ They reported that the volume expansion is to be expected and the $\mathrm{Fe}-\mathrm{H}$ interaction occurs mainly via the $\mathrm{Fe}$ $4 \mathrm{~s}$ and $\mathrm{H} 1 \mathrm{~s}$ orbitals. A charge transfer of $\sim 0.6 e$ from $\mathrm{Fe}$ to $\mathrm{H}$ leads to a decrease in the metallic bond strength. Assuming similarity to the case in $\mathrm{Fe}-\mathrm{H}$ systems, the addition of $\mathrm{H}$ into NiMnIn might also make the system less metallic and thus cause a decrease in $e / a$. In accordance with the general dependence of $T_{\mathrm{M}}$ on $e / a,{ }^{[40,41]} T_{\mathrm{M}}$ decreases with $\mathrm{H}$ doping.

Shown in Fig. 13 are the $\Delta S$ curves calculated based on Maxwell's relations. ${ }^{[1-3]}$ With increasing magnetic field, the inverse $\Delta S$ peak gradually broadens toward lower temperatures. The maximal $\Delta S$ is $17.2 \mathrm{~J} \cdot \mathrm{kg}^{-1} \cdot \mathrm{K}^{-1}, 13.0 \mathrm{~J} \cdot \mathrm{kg}^{-1} \cdot \mathrm{K}^{-1}$ at $246 \mathrm{~K}, 219 \mathrm{~K}$, and the temperature span is $17 \mathrm{~K}, 22.5 \mathrm{~K}$ under a $5 \mathrm{~T}$ field for $\mathrm{Ni}_{51} \mathrm{Mn}_{32.4} \mathrm{In}_{16.6}$ and $\mathrm{Ni}_{51} \mathrm{Mn}_{32.4} \mathrm{In}_{16.6} \mathrm{H}_{5.2}$, respectively. For the hydrogenated sample, the $\Delta S$ magnitude becomes somewhat smaller, but the temperature span becomes wider.

Our studies also reveal that the $\mathrm{H}$ content can be controlled by adjusting the annealing temperature and the gas pressure. For a close composition $\mathrm{Ni}_{51} \mathrm{Mn}_{32.8} \mathrm{In}_{16.2}$, the $\mathrm{H}$ content was controllably tuned to be $\delta=1.4$. A similar shift of $T_{\mathrm{M}}$ to lower temperatures and the enhancement of the saturated magnetization of the martensitic phase were observed 
in $\mathrm{Ni}_{51} \mathrm{Mn}_{32.8} \mathrm{In}_{16.2} \mathrm{H}_{1.4}$ hydride. However, the shift of $T_{\mathrm{M}}$ was only $\sim 6 \mathrm{~K}$ due to the small amount of $\mathrm{H}$ atoms. This result suggests that the $T_{\mathrm{M}}$ can be tunable through controlling the $\mathrm{H}$ content. The maximal $\Delta S$ is $\sim 19.2 \mathrm{~J} \cdot \mathrm{kg}^{-1} \cdot \mathrm{K}^{-1}$, $\sim 17.5 \mathrm{~J} \cdot \mathrm{kg}^{-1} \cdot \mathrm{K}^{-1}$ at $\sim 253 \mathrm{~K}, \sim 245 \mathrm{~K}$, and the temperature span is $\sim 17 \mathrm{~K}, \sim 20 \mathrm{~K}$ under a field change of $0-5 \mathrm{~T}$ for $\mathrm{Ni}_{51} \mathrm{Mn}_{32.8} \mathrm{In}_{16.2}$ and $\mathrm{Ni}_{51} \mathrm{Mn}_{32.8} \mathrm{In}_{16.2} \mathrm{H}_{1.4}$, respectively. Similar to the case in $\mathrm{Ni}_{51} \mathrm{Mn}_{32.4} \mathrm{In}_{16.6}$, the $\Delta S$ magnitude is slightly reduced while the temperature span becomes wider upon $\mathrm{H}$ doping. The evaluated refrigerant capacity (RC) remains nearly unchanged.
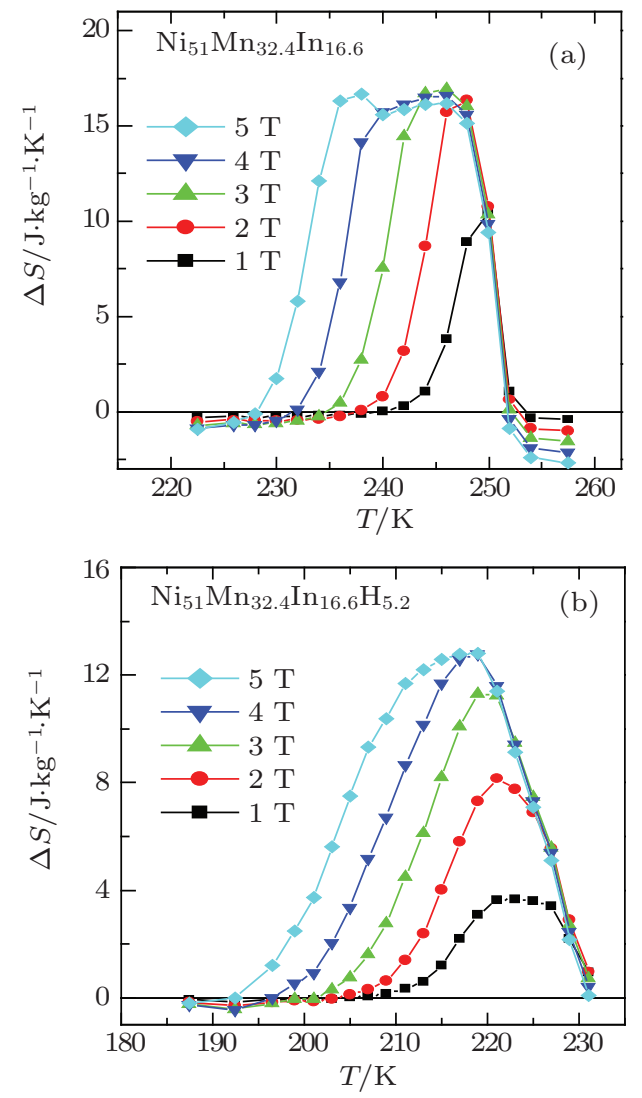

Fig. 13. Magnetic entropy change $\Delta S$ as a function of temperature under different magnetic fields for (a) $\mathrm{Ni}_{51} \mathrm{Mn}_{32.4} \mathrm{In}_{16.6}$ and (b) $\mathrm{Ni}_{51} \mathrm{Mn}_{32.4} \mathrm{In}_{16.6} \mathrm{H}_{5.2}$ samples. ${ }^{[59]}$

\subsection{Effect of post-annealing on atomic ordering and mag- netic entropy change in NiMnCoIn metamagnetic al- loys}

The NiMn-based metamagnetic alloys are usually prepared by an arc-melting technique followed by annealing at $1173 \mathrm{~K}$ and quenching in ice water. Hence, the as-prepared samples contain stress and defects. Additional annealing can relax the stress and modify the atomic ordering and the $\mathrm{Mn}-$ Mn distance, as well as the lattice symmetry. As a result, the Mn-Mn exchange coupling, the Brillouin zone boundary, and hence $T_{\mathrm{M}}$ and the metamagnetic behavior are changed. The previous investigations ${ }^{[69,70]}$ indicated that additional annealing at temperatures $\geq 350{ }^{\circ} \mathrm{C}$ can change the microstructure and the magnetic properties. But we noticed that $T_{\mathrm{M}}$ and the metamagnetic behavior sometimes disappear upon annealing due to the kinetic arrest effect. ${ }^{[69]}$ Recently, we carried out investigations of the low temperature annealing effect on atomic ordering and metamagnetic behavior. Our studies ${ }^{[55,63]}$ indicate that proper annealing at low temperatures $\left(\leq 300^{\circ} \mathrm{C}\right)$ can tune $T_{\mathrm{M}}$ around room temperature while keeping the strong metamagnetic properties; thus large $\mathrm{MCE}^{[63]}$ and $\mathrm{MR}^{[55]}$ effect can be realized over an extended temperature range around room temperature.

$\mathrm{Ni}_{45} \mathrm{Co}_{5} \mathrm{Mn}_{50-x} \operatorname{In}_{x}(x=13.3,13.4,13.5)$ alloys were prepared by an arc-melting technique in one batch followed by annealing at $1173 \mathrm{~K}$ for $24 \mathrm{~h}$ and quenching in ice water. Small pieces were cut from the as-prepared ingots and further annealed at $250{ }^{\circ} \mathrm{C}$ or $300{ }^{\circ} \mathrm{C}$ for $3 \mathrm{~h}$ and then quenched in ice water. The resulted samples are denoted as $250{ }^{\circ} \mathrm{C}$-annealed and $300{ }^{\circ} \mathrm{C}$-annealed samples, respectively. Our studies on the effects of low temperature annealing also reveal the thermal stability of the novel compositions.

Neutron (Fig. 14(a)) and X-ray (Fig. 14(b)) diffraction measurements reveal that the austenitic phase appears in the $L 2_{1}$-type order structure (space group: $F m-3 m$ ) while the martensitic phase in the body-centered tetragonal (bct; space group: $14 / \mathrm{mmm}$ ) structure, noting the appearance of characteristic peaks (111) and (311) of the $L 2{ }_{1}$-type order (see the inset of Fig. 14(a)).
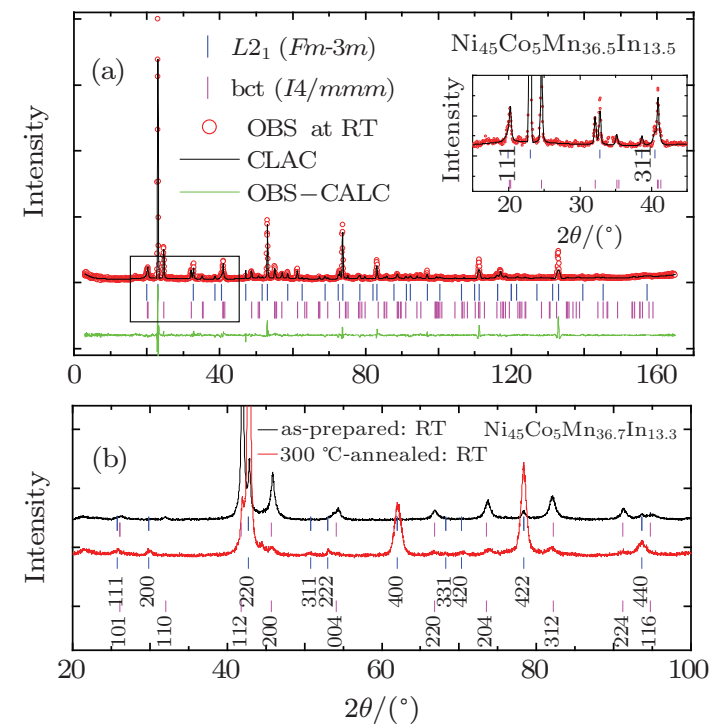

Fig. 14. (a) Observed (OBS) and calculated (CALC) intensities for neutron diffraction data collected at room temperature (wavelength $1.1968 \AA$ A by a $\mathrm{Ge}(733)$ monochromator) for $\mathrm{Ni}_{45} \mathrm{Co}_{5} \mathrm{Mn}_{36.5} \mathrm{In}_{13.5}$. Inset shows the appearance of characteristic peaks (111) and (311) of the $L 2_{1}$ type order. (b) XRD patterns of the as-prepared and $300{ }^{\circ} \mathrm{C}$-annealed samples for $\mathrm{Ni}_{45} \mathrm{Co}_{5} \mathrm{Mn}_{36.7} \mathrm{In}_{13.3}$ collected at room temperature. ${ }^{[63]}$

According to the simplest and most classical method, ${ }^{[81,82]}$ the degree of the $L 2_{1}$-type order, $S_{\mathrm{H}}$, can be determined from the XRD intensity ratio of the superlattice and the fundamental reflections $I(111) / I(220)$ in the following way:

$$
S_{\mathrm{H}}^{2}=\{I(111) / I(220)\}_{\mathrm{exp}} /\{I(111) / I(220)\}_{\mathrm{cal}},
$$


where $I$ is the peak intensity of the X-ray diffraction, and notations exp and cal mean experimental and calculation, respectively.

The calculated intensity ratio $[I(111) / I(220)]_{\text {cal }}$ is crucially dependent on the atomic occupations. We assumed that all Co atoms occupy the $\mathrm{Ni}$ positions and the rest of the $\mathrm{Mn}$ atoms (36.7-25 in $\mathrm{Ni}_{45} \mathrm{Co}_{5} \mathrm{Mn}_{36.7} \operatorname{In}_{13.3}$ ) occupy the In positions, and then calculated the order degrees of the samples. The obtained $S_{\mathrm{H}}$ of the $L 2_{1}$ order is 0.86 and 0.77 for the asprepared and the $300{ }^{\circ} \mathrm{C}$-annealed $\mathrm{Ni}_{45} \mathrm{Co}_{5} \mathrm{Mn}_{36.7} \mathrm{In}_{13.3}$, respectively. One can find that the degree of the $L 2_{1}$ order gets smaller with low temperature annealing.

Along with the reduction of the $L 2_{1}$ order degree, we found that the $T_{\mathrm{M}}$ shifts to lower temperatures, and the shift gap can be as large as $30 \mathrm{~K}$ when the sample is annealed at $300{ }^{\circ} \mathrm{C}$ for $3 \mathrm{~h}$. Meanwhile, a slight widening of the hysteresis gap appears for the annealed samples. The shift of $T_{\mathrm{M}}$ can be ascribed to the stress relaxation and the atomic order modification upon annealing. The stress formed during the quenching process is relaxed to some extent depending on the annealing temperature and duration, which may modify atomic site/ordering, Mn-Mn distance, and lattice symmetry. As a result, the Mn-Mn exchange coupling, the Fermi surface, and the Brillouin zone boundary may be changed. ${ }^{[83,84]}$ These results together lead to the reduction of $T_{\mathrm{M}}$. From thermal magnetization curves, we notice that the magnetization change across the martensitic transformation under $5 \mathrm{~T}$ is nearly the same $\left(\sim 100 \mathrm{~A} \cdot \mathrm{m}^{2} \cdot \mathrm{kg}^{-1}\right)$ for the as-prepared, $250{ }^{\circ} \mathrm{C}$-annealed, and $300{ }^{\circ} \mathrm{C}$-annealed $\mathrm{Ni}_{45} \mathrm{Co}_{5} \mathrm{Mn}_{36.7} \mathrm{In}_{13.3}$ samples. The resulting large Zeeman energy $\mu_{0} \Delta M \cdot H$ pushes $T_{\mathrm{M}}$ to lower temperatures at a rate of $4.0 \mathrm{~K} / \mathrm{T}, 5.4 \mathrm{~K} / \mathrm{T}$, and $6.8 \mathrm{~K} / \mathrm{T}$, respectively. The driving rate does not drop but shows a small increase upon annealing. These findings demonstrate that the annealed samples still retain strong metamagnetic properties. Hence, large MCE and MR effect can be expected even for the annealed samples.

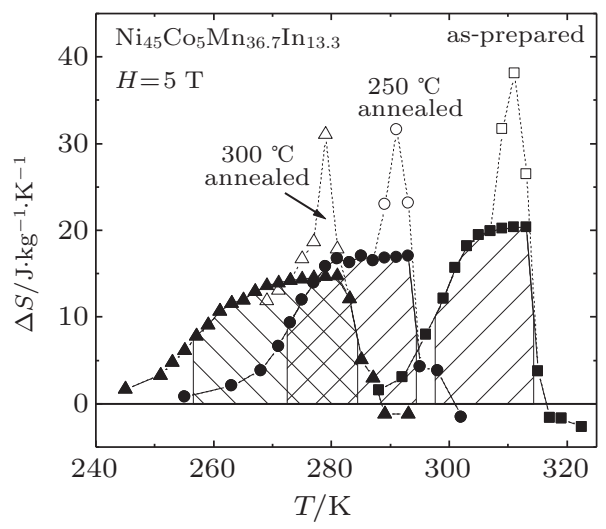

Fig. 15. Magnetic entropy change $\Delta S$ as a function of temperature under a field change of $0-5 \mathrm{~T}$ for the as-prepared, $250{ }^{\circ} \mathrm{C}$-annealed, and $300{ }^{\circ} \mathrm{C}$-annealed $\mathrm{Ni}_{45} \mathrm{Co}_{5} \mathrm{Mn}_{36.7} \mathrm{In}_{13.3}$ samples. The solid line and the patterned areas correspond to the effective $\Delta S$ and the refrigeration capacity, respectively. ${ }^{[63]}$
Shown in Fig. 15 are the $\Delta S$ curves obtained by using Maxwell's relations. The effective inverse $\Delta S$ (the plateau height, not the spike ${ }^{[72,73]}$ ) is about $\sim 20 \mathrm{~J} \cdot \mathrm{kg}^{-1} \cdot \mathrm{K}^{-1}, \sim$ $17 \mathrm{~J} \cdot \mathrm{kg}^{-1} \cdot \mathrm{K}^{-1}$, and $\sim 15 \mathrm{~J} \cdot \mathrm{kg}^{-1} \cdot \mathrm{K}^{-1}$, and the corresponding half-peak width is $\sim 20 \mathrm{~K}, \sim 27 \mathrm{~K}$, and $\sim 34 \mathrm{~K}$, for the as-prepared, $250{ }^{\circ} \mathrm{C}$-annealed, and $300{ }^{\circ} \mathrm{C}$-annealed $\mathrm{Ni}_{45} \mathrm{Co}_{5} \mathrm{Mn}_{36.7} \mathrm{In}_{13.3}$ samples, respectively. Although the magnitude of the effective $\Delta S$ is somewhat reduced, the temperature span is broadened.

We also investigated the transport properties for the asprepared and the annealed samples. ${ }^{[55]}$ The MR is $-67 \%$, $-72 \%$, and $-69 \%$, and the temperature span is $20 \mathrm{~K}, 29 \mathrm{~K}$, and $32 \mathrm{~K}$, for the as-prepared, $250{ }^{\circ} \mathrm{C}$-annealed, and $300{ }^{\circ} \mathrm{C}$ annealed $\mathrm{Ni}_{45} \mathrm{Co}_{5} \mathrm{Mn}_{36.6} \mathrm{In}_{13.4}$ samples, respectively. Note that annealing at low temperature can slightly enhance the MR and broaden the temperature region of the large MR.

Furthermore, we fabricated ribbons with $B 2$ structure through forced disordering of atomic occupations by the meltspun technique. ${ }^{[54]}$ The $T_{\mathrm{M}}$ of $\mathrm{Ni}_{45} \mathrm{Co}_{5} \mathrm{Mn}_{36.5} \mathrm{In}_{13.5}$ bulk and two ribbons fabricated by two different melt-spun speeds $\left(10 \mathrm{~m} \cdot \mathrm{s}^{-1}\right.$ and $\left.20 \mathrm{~m} \cdot \mathrm{s}^{-1}\right)$ is located at $314 \mathrm{~K}, 256 \mathrm{~K}$, and $236 \mathrm{~K}$, respectively. This confirms that $T_{\mathrm{M}}$ reduces with the reduction of the degree of atomic ordering. Our research shows that the metamagnetic behavior weakens for both ribbons, and their $\Delta S$ decreases significantly. The effective $\Delta S_{\text {effe }}$ is $6.4 \mathrm{~J} \cdot \mathrm{kg}^{-1} \cdot \mathrm{K}^{-1}$ and $5.9 \mathrm{~J} \cdot \mathrm{kg}^{-1} \cdot \mathrm{K}^{-1}$ under a field change of 0-5 $\mathrm{T}$ for $10 \mathrm{~m} \cdot \mathrm{s}^{-1}$ and $20 \mathrm{~m} \cdot \mathrm{s}^{-1}$ ribbons, respectively. By employing magnetic measurements, we observed abnormal increases in the saturation magnetization of low temperature martensite for these two ribbons. A detailed analysis indicates that there are two reasons. One is the enhancement of the FM exchange interaction between $\mathrm{Mn}-\mathrm{Mn}$ caused by the atomic disordering in the martensite; the other is the contribution from the residual FM parent phase due to the incomplete transition caused by the increase of remnant internal stress, which hinders the martensitic transition. In addition, we found that the $20 \mathrm{~m} \cdot \mathrm{s}^{-1}$ ribbon shows an MR as large as $-60 \%$ in a wide temperature span from $10 \mathrm{~K}$ to $175 \mathrm{~K}$, which is closely related with the enhancement of saturated magnetization at low temperature.

\subsection{Magnetoresistance and magnetocaloric proper- ties involving strong metamagnetic behavior in $\mathrm{Ni}_{45}\left(\mathrm{Co}_{1-x} \mathrm{Fe}_{x}\right)_{5} \mathrm{Mn}_{36.6} \mathrm{In}_{13.4}$ with $\mathrm{Fe} / \mathrm{Co}$ co-doping}

The previous studies indicate that the Co doping can work as an FM activator through modulating the atomic occupations and enhance the FM properties of the parent phase in many Mn-rich metamagnetic NiMnCoZ ( $Z=\mathrm{In}, \mathrm{Sb}, \mathrm{Sn}, \mathrm{Ga})$ alloys. ${ }^{[49,50]}$ However, the $\mathrm{Fe}$ atom acts in an opposite way, even though it is a close neighbor of Co in the periodic table and has a similar number of valence electrons and a similar atomic radius. In most cases, the incorporation of $\mathrm{Fe}$ atoms 
weakens the FM properties due to the introduced AFM FeMn coupling. Iron is not a good choice to optimize functions (such as shape memory effect, MCE, MR) and adjust the transition temperatures. It has been experimentally observed ${ }^{[61]}$ that the substitution of $\mathrm{Fe}$ for $\mathrm{Ni}$ in stoichiometric $\mathrm{Ni}_{2} \mathrm{MnGa}$ causes a sharp decrease of magnetization. However, a recent investigation $^{[61]}$ indicates that with the substitution of Fe for $\mathrm{Ni}$ in Mn-rich NiMnGa ribbons, the magnetization increases greatly rather than decreases, implying that the Mn-Mn AFM coupling has been changed into an FM coupling.

We introduced $\mathrm{Fe}$ atoms in the functional composition $\mathrm{Ni}_{45} \mathrm{Co}_{5} \mathrm{Mn}_{36.6} \mathrm{In}_{13.4}{ }^{[47]}$ and investigated the effect of $\mathrm{Co} / \mathrm{Fe}$ co-doping on atomic occupations, martensitic transformation, and functional properties. ${ }^{[41]}$ Quinary alloys $\mathrm{Ni}_{45}\left(\mathrm{Co}_{1-x} \mathrm{Fe}_{x}\right)_{5} \mathrm{Mn}_{36.6} \mathrm{In}_{13.4}(x=0,0.02,0.05)$ were prepared by an arc-melting technique. XRD patterns detected the coexistence of body-centered tetragonal martensitic structure and body-centered cubic austenitic structure for all samples, noting that $T_{\mathrm{M}}$ is close to room temperature. Upon Fe doping, the lattice parameter $a$ of the austenitic structure is nearly unchanged (note that $\mathrm{Fe}$ has an atomic radius similar to that of $\mathrm{Co}$ ), but the parameter ratio $c / a$ of the bct martensitic structure monotonously decreases with $\mathrm{Fe}$ doping. The reduction ratio is about $0.83 \%$ as the $\mathrm{Fe}$ content increases from $x=0$ to $x=0.05$, indicating that the symmetry of the bct martensitic structure is enhanced.

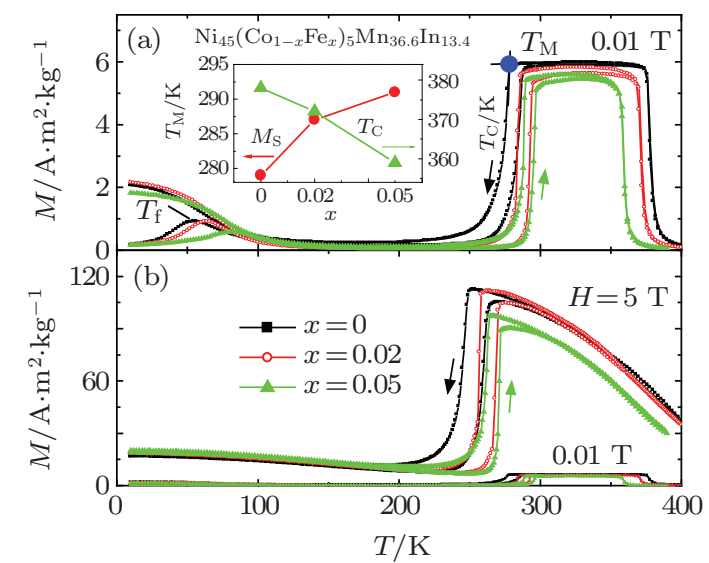

Fig. 16. (a) Temperature dependence of ZFC and FC magnetizations $(M-T$ curves) measured under $0.01 \mathrm{~T}$, and (b) the comparison of $M-T$ curves measured under $5 \mathrm{~T}$ and $0.01 \mathrm{~T}$ for $\mathrm{Ni}_{45}\left(\mathrm{Co}_{1-x} \mathrm{Fe}_{x}\right)_{5} \mathrm{Mn}_{36.6} \mathrm{In}_{13.4}$ $(x=0,0.02,0.05)$ alloys. Inset of panel (a) displays the dependences of the martensitic transformation temperature $T_{\mathrm{M}}$ and the Curie temperature $T_{\mathrm{C}}$ of the parent phase on the Fe content. Arrows indicate heating and cooling paths. ${ }^{[53]}$

Figure 16(a) displays temperature dependent ZFC and FC magnetizations ${ }^{[65]}$ measured under $0.01 \mathrm{~T}$. One can find that the $T_{\mathrm{C}}$ of the parent phase shifts notably to a lower temperature while the martensitic temperature $T_{\mathrm{M}}$ shifts to a higher temperature with Fe doping. This fact suggests that a higher Fe content stabilizes the martensitic phase and the PM parent phase. The inset of Fig. 16(a) schematically shows the dependences of $T_{\mathrm{M}}$ and $T_{\mathrm{C}}$ on the Fe content. Note that both $T_{\mathrm{M}}$ and $T_{\mathrm{C}}$ are sensitive to the $\mathrm{Fe}$ concentration. A small amount of $\mathrm{Fe}$ doping $(x=0.02)$ can cause a big shift $(8 \mathrm{~K})$ of the $T_{\mathrm{M}}$ from $279 \mathrm{~K}$ to $287 \mathrm{~K}$, and a shift $(6 \mathrm{~K})$ of the $T_{\mathrm{C}}$ from $378 \mathrm{~K}$ to $372 \mathrm{~K}$. Further increasing the Fe doping to $x=0.05$ does not shift $T_{\mathrm{M}}$ very much ( $4 \mathrm{~K}$ from $287 \mathrm{~K}$ to $291 \mathrm{~K}$ ) but notably lowers $T_{\mathrm{C}}$ from $372 \mathrm{~K}$ at $x=0.02$ to $359 \mathrm{~K}$ at $x=0.05$. Figure 16 (b) presents the comparison of $M-T$ curves measured under $5 \mathrm{~T}$ and $0.01 \mathrm{~T}$. Note that a small amount of Fe doping $(x=0.02)$ does not cause much change of the saturated magnetization for either the martensitic or the parent phase. Further increasing Fe content to $x=0.05$ causes a slight drop of the magnetization of the parent phase, but the magnetization of the martensitic phase remains unchanged. The difference of magnetization $(\Delta M)$ across the martensitic transformation remains large, which demonstrates that the Fe-doped samples retain strong metamagnetic properties.

We examined the change of valence electron concentration, $e / a$, with $\mathrm{Fe}$ doping in $\mathrm{Ni}_{45}\left(\mathrm{Co}_{1-x} \mathrm{Fe}_{x}\right)_{5} \mathrm{Mn}_{36.6} \mathrm{In}_{13.4}$. The change of $e / a$ is very small due to the small amount of Fe doping and the close number of valence electrons between $\mathrm{Fe}$ and Co. The maximal change of $e / a$ is only $0.03 \%$ as the $\mathrm{Fe}$ content increases from $x=0$ to $x=0.05$. With a slight reduction of $e / a$ with Fe doping, $T_{\mathrm{M}}$ does not decrease but shows a notable increase; meanwhile the $T_{\mathrm{C}}$ of the parent phase notably decreases. This fact conflicts with the general dependences of $T_{\mathrm{M}}$ and $T_{\mathrm{C}}$ on $e / a .^{[40,41]}$ So we conclude that the little change of $e / a$ due to Fe doping does not dominate the alteration of $T_{\mathrm{M}}$ and $T_{\mathrm{C}}$. However, the fact that the average $e / a$ changes little does not mean that the electronic structure is unchanged with Fe doping. The comprehensive effect from the changes of electronic structure and atomic occupations, altering of structure symmetry, and introduced Fe-Mn AFM coupling must be responsible for the shifts of $T_{\mathrm{M}}$ and $T_{\mathrm{C}}$ and the change of the magnetic properties.

To help one intuitively understand the magnetic structure and the atomic occupation upon Fe doping, figure 17 schematically displays a rough schema of the magnetic structure and the atomic sites of cubic austenite phase for $\mathrm{Mn}$-rich $\mathrm{Ni}_{50} \mathrm{Mn}_{25+x} \mathrm{In}_{25-x}$ and Fe/Co co-doped $\mathrm{Ni}_{50-y}(\mathrm{Fe}, \mathrm{Co})_{y} \mathrm{Mn}_{25+x} \mathrm{In}_{25-x}$. In Mn-rich alloys, the extra Mn occupying the In sites prefers an AFM coupling with the nearest $\mathrm{Mn}$ atoms in both the austenite and the martensite phases $^{[85]}$ (Fig. 17(a)). Cobalt atoms work as an FM activator and tune the Mn-Mn AFM into an FM coupling in Mn-rich Heusler alloys, ${ }^{[49,50]}$ where the magnetic moment is mainly confined to the $\mathrm{Mn}$ site while $\mathrm{Co}$ and $\mathrm{Ni}$ contribute little to the total moment. ${ }^{[86]}$ The arrows in Fig. 17 indicate the direction of the magnetic moment. The small arrow at the Co (Ni) site indicates a small moment. We suppose that the introduced 
$\mathrm{Fe}$ atoms substituting for Co randomly occupy the Ni sites. Cobalt atoms tune the Mn-Mn coupling from AFM to FM in general, while Fe atoms play a similar role in Mn-rich NiFeMnGa ribbons ${ }^{[61]}$ and assist the tuning process, but the $\mathrm{Fe}-\mathrm{Mn}$ coupling is still AFM (Fig. 17(b)). As a result, the magnetization of the parent phase remains large and the metamagnetic behavior remains strong upon $\mathrm{Fe}$ doping. However, due to the Fe-Mn AFM coupling, the $T_{\mathrm{C}}$ of the austenite phase decreases and the saturated magnetization reduces as the amount of $\mathrm{Fe}$ doping becomes large.

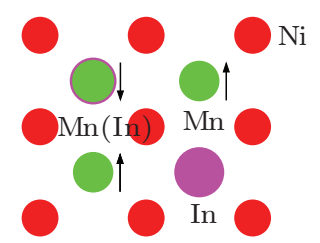

(a) $\mathrm{Ni}_{50} \mathrm{Mn}_{25+x} \operatorname{In}_{25-x}$

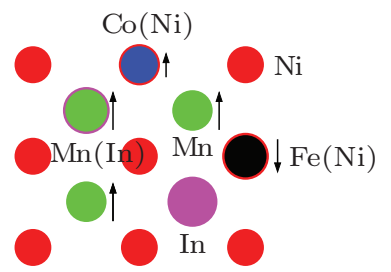

(b) $\mathrm{Ni}_{50-y}(\mathrm{Co}, \mathrm{Fe})_{y} \mathrm{Mn}_{25+x} \operatorname{In}_{25-x}$
Fig. 17. Magnetic structure sketch and atomic sites of the top view of the cubic austenite phase for (a) Mn-rich $\mathrm{Ni}_{50} \mathrm{Mn}_{25+x} \mathrm{In}_{25-x}$ and (b) $\mathrm{Fe} / \mathrm{Co}$ co-doped $\mathrm{Ni}_{50-y}(\mathrm{Fe}, \mathrm{Co})_{y} \mathrm{Mn}_{25+x} \mathrm{In}_{25-x}$. Arrows indicate the moment direction. $\mathrm{Mn}(\mathrm{In})$ indicates that the In site is occupied by $\mathrm{Mn}$. $\mathrm{Co}(\mathrm{Ni}) / \mathrm{Fe}(\mathrm{Ni})$ indicates that the Ni site is occupied by $\mathrm{Co} / \mathrm{Fe} .^{[53]}$

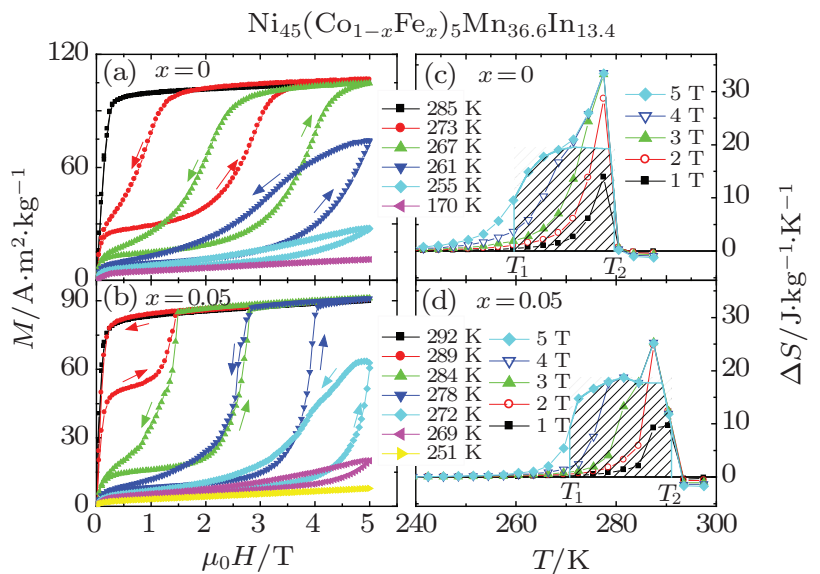

Fig. 18. Magnetization isotherms for $\mathrm{Ni}_{45}\left(\mathrm{Co}_{1-x} \mathrm{Fe}_{x}\right)_{5} \mathrm{Mn}_{36.6} \mathrm{In}_{13.4}$ ((a) $x=0$ and (b) $x=0.05$ ), and the magnetic entropy change $\Delta S$ as a function of temperature under different magnetic fields for (c) $x=0$ and (d) $x=0.05$. The shadow area indicates the direct RC evaluated by integrating the area under the $\Delta S$ curve from $T_{1}$ to $T_{2}$ $\left(T_{2}-T_{1}\right.$ : half-maximum width). Arrows indicate field changing paths. ${ }^{[53]}$

Figures 18(a) and 18(b) shows the representative magnetization isotherms measured around the martensitic transition for $x=0$ and 0.05 samples, respectively. Note that the field-induced metamagnetic transition becomes notably steeper with Fe doping but the hysteresis loss (enclosed area in a field cycle) gets smaller. The maximal hysteresis loss is $153 \mathrm{~J} \cdot \mathrm{kg}^{-1}$ and $110 \mathrm{~J} \cdot \mathrm{kg}^{-1}$ for samples $x=0$ and 0.05 , respectively. Figures 18 (c) and 18(d) show the $\Delta \mathrm{S}$ curves calculated by using Maxwell's equations. The effective $\Delta S$ (not the spike, but the high plateau value $\left.{ }^{[72,73]}\right)$ is $19.5 \mathrm{~J} \cdot \mathrm{kg}^{-1} \cdot \mathrm{K}^{-1}(\sim 269 \mathrm{~K})$ and $18.7 \mathrm{~J} \cdot \mathrm{kg}^{-1} \cdot \mathrm{K}^{-1}(\sim 281 \mathrm{~K})$ under a field change of $0-5 \mathrm{~T}$ for $x=0$ and 0.05 samples, respectively. Note that the effective $\Delta S$ is nearly unchanged upon Fe doping, and the effective refrigerator capacity of the Fe-doped sample $(x=0.05)$ is enhanced by $\sim 15 \%$ compared to that of its mother compound due to the reduction of the hysteresis loss.

With $T_{\mathrm{M}}$ shifting to a lower temperature under an external field, a negative $\mathrm{MR} \sim\left(R_{5 \mathrm{~T}}-R_{0 \mathrm{~T}}\right) / R_{0 \mathrm{~T}}$ is observed. ${ }^{[53]}$ The maximal MR related to the field-driven metamagnetic transition under $5 \mathrm{~T}$ is about $-76.5 \%(244 \mathrm{~K}),-73.0 \%(262 \mathrm{~K})$, and $-73.2 \%(266 \mathrm{~K})$ for $x=0,0.02,0.05$ samples, respectively. The MR magnitude remains large while $T_{\mathrm{M}}$ varies near room temperature with tuning Fe doping. The temperature scope is about $50 \mathrm{~K}$ from $\sim 240 \mathrm{~K}$ to $\sim 290 \mathrm{~K}$ where the large $\mathrm{MR}$ (from $-70 \%$ to $-77 \%$ ) appears.

\section{Summary}

1) A positive $\Delta S$ as large as $4.1 \mathrm{~J} \cdot \mathrm{kg}^{-1} \cdot \mathrm{K}^{-1}$ under a field change of 0-0.9 $\mathrm{T}$ was first observed in a conventional polycrystalline alloy $\mathrm{Ni}_{51.5} \mathrm{Mn}_{22.7} \mathrm{Ga}_{25.8}$ with martensitic transition $T_{\mathrm{M}}$ at $\sim 197 \mathrm{~K}$ in 2000 . Both the martensite and the austenite exhibit the FM behavior, but the enhanced magnetic anisotropy due to the lower structural symmetry of the martensite makes it harder for the magnetization to saturate than that in the austenite. The fundamental change of magnetic properties across the martensitic transition is responsible for the large $\Delta S$.

2) Through adjusting the Ni:Mn:Ga ratio to affect the valence electron concentration $e / a, T_{\mathrm{M}}$ was successfully tuned to room temperature, and a large magnitude negative $\Delta S$ was observed in a single crystal $\mathrm{Ni}_{52.6} \mathrm{Mn}_{23.1} \mathrm{Ga}_{24.3}$. Because of the change of magnetic anisotropy upon the martensitic transition, cross points appear in the $M-H$ curves measured at different temperatures. It is located at $B \sim 0.23 \mathrm{~T}$ for $\mathrm{Ni}_{52.6} \mathrm{Mn}_{23.1} \mathrm{Ga}_{24.3}$ single crystal, and the magnitude of negative $\Delta S$ reaches $18.0 \mathrm{~J} \cdot \mathrm{kg}^{-1} \cdot \mathrm{K}^{-1}$, which is roughly comparable with that of $\mathrm{Gd}_{5} \mathrm{Si}_{2} \mathrm{Ge}_{2}$ and notably exceeds that of $\mathrm{Gd}$ near room temperature.

3) NiMn-based metamagnetic Heusler alloys with rich Mn content show a huge shape memory effect and a different mechanism from that of the conventional alloys. $\mathrm{Ni}_{50} \mathrm{Mn}_{34} \mathrm{In}_{16}$ is the only metamagnetic composition that exhibits a field-induced structural transition in $\mathrm{Ni}_{50} \mathrm{Mn}_{50-y} \mathrm{In}_{y}$, but its $T_{\mathrm{M}}$ locates at $180 \mathrm{~K}$, still far below the room temperature. Through changing the Mn content but fixing the In content, a strong metamagnetic behavior was realized in the close compositions $\mathrm{Ni}_{50-x} \mathrm{Mn}_{35+x} \mathrm{In}_{15}$. For an optimized composition with $T_{\mathrm{M}}$ at $285 \mathrm{~K}$, a huge $\Delta S\left(\sim 21 \mathrm{~J} \cdot \mathrm{kg}^{-1} \cdot \mathrm{K}^{-1}\right)$ involving the field-induced metamagnetic behavior was observed near room temperature. Its temperature span could be as wide as $\sim 15 \mathrm{~K}$. 
4) Through tuning compositions around the ratio $\mathrm{Ni}_{50} \mathrm{Mn}_{34} \mathrm{In}_{16}$, a small thermal hysteresis $(<2 \mathrm{~K})$ was observed in metamagnetic alloys $\mathrm{Ni}_{51} \mathrm{Mn}_{49-x} \mathrm{In}_{x}(x=15.6,16.0$, 16.2). However, the magnetic hysteresis is not trivial but can be as large as $\sim 77 \mathrm{~J} \cdot \mathrm{kg}^{-1}(258 \mathrm{~K})$ in a field cycle. The different hysteresis behaviors in temperature and field cycles may indicate the different nucleation mechanisms under different external perturbations.

5) For the metamagnetic alloys, the Co doping can work as an FM activator through modulating the atomic occupations and can enhance the difference of Zeeman energy $\mu_{0} \Delta M \cdot H$ across the martensitic transformation. We studied MR and MCE for the novel compositions $\mathrm{Ni}_{45} \mathrm{Co}_{5} \mathrm{Mn}_{50-x} \mathrm{In}_{x}$ $(x=13.3,13.4,13.5)$ that show extremely huge FM shape memory effects due to the incorporation of Co atoms. An MR as large as $-80 \%$ was observed along with the field-induced metamagnetic transitions. This can be ascribed to the electron scattering around the grain boundary, the electron-spin scattering, and the changes of conducting electronic density of state. Associated with the metamagnetic behavior, the maximal $\Delta S$ was about $\sim 22 \mathrm{~J} \mathrm{~J} \cdot \mathrm{kg}^{-1} \cdot \mathrm{K}^{-1}$ under a field change of $0-5 \mathrm{~T}$.

6) By inserting hydrogen into metamagnetic alloys $\mathrm{Ni}_{51} \mathrm{Mn}_{49-x} \operatorname{In}_{x}(x=16.2,16.6)$, the interstitial compounds $\mathrm{Ni}_{51} \mathrm{Mn}_{49-x} \mathrm{In}_{x} \mathrm{H}_{\delta}$ were fabricated. The introduction of $\mathrm{H}$ atoms does not change the $L 2_{1}$ structure but shifts $T_{\mathrm{M}}$ to a lower temperature. Similar to the $\mathrm{Fe}-\mathrm{H}$ system, where the charge transfer from $\mathrm{Fe}$ to $\mathrm{H}$ leads to a decrease in metallic bond strength, the addition of $\mathrm{H}$ into NiMnIn may also make the system less metallic and hence cause a decrease in $e / a$ and $T_{\mathrm{M}}$. Furthermore, the Mn-Mn distance is elongated upon the interstitial $\mathrm{H}$ doping. As a result, the martensitic phase favors the FM coupling, thus leading to an enhancement of the saturated magnetization of the martensitic state. However, $\mathrm{Ni}_{51} \mathrm{Mn}_{49-x} \mathrm{In}_{x} \mathrm{H}_{\delta}$ compounds still retain the metamagnetic properties and large MCE. By controlling the $\mathrm{H}$ content, an extended temperature range having large MCE can be achieved.

7) Through low temperature annealing, a modulation of atomic ordering, martensitic transition temperature $T_{\mathrm{M}}$, and a metamagnetic behavior was realized for the metamagnetic alloys $\mathrm{Ni}_{45} \mathrm{Co}_{5} \mathrm{Mn}_{50-x} \operatorname{In}_{x}(x=13.3,13.4)$. According to the classical method, the degree of the $L 2_{1}$-type order, $S_{\mathrm{H}}$, was determined from the XRD intensity ratio of the superlattice and the fundamental reflections $I(111) / I(220)$. It was found that $S_{\mathrm{H}}$ reduces from 0.86 to 0.77 and $T_{\mathrm{M}}$ reduces from $319 \mathrm{~K}$ to $289 \mathrm{~K}$ when the as-prepared sample is further post-annealed at $300^{\circ}$ for $1 \mathrm{~h}$. Meanwhile, the strong metamagnetic behavior is retained, and hence the MR and the MCE associated with the metamagnetic transition remain large.

8) The effects of Fe doping on atomic occupation, meta- magnetic behavior, magnetocaloric and transport properties were investigated in $\mathrm{Ni}_{45}\left(\mathrm{Co}_{1-x} \mathrm{Fe}_{x}\right)_{5} \mathrm{Mn}_{36.6} \mathrm{In}_{13.4}$ metamagnetic alloys. The introduced $\mathrm{Fe}$ atom plays a role similar to that of $\mathrm{Co}$ and assists the conversion of the Mn-Mn coupling from AFM to FM. As a result, a small amount of Fe doping can tune $T_{\mathrm{M}}$ while maintaining the strong metamagnetic behavior, which indicates excellent functions at tunable temperatures, such as shape memory effect, MR, and MCE. A more interesting finding is that magnetic hysteresis gets smaller with $\mathrm{Fe}$ doping, as a result, the effective refrigeration capacity can be enhanced by $\sim 15 \%$ when the Fe doping is $x=0.05$.

\section{Acknowledgement}

Use of copyrighted Figs. 2, 3, and 6-18 is permitted by the American Institute of Physics. Use of Figs. 4 and 5 is permitted by the American Physical Society.

\section{References}

[1] Tishin A M and Spichkin Y I 2003 The Magnetocaloric Effect and Its Applications (Bristol: Institute of Physics)

[2] Gschneidner K A Jr, Pecharsky V K and Tsokol A O 2005 Rep. Prog. Phys. 681479

[3] Bruck E 2008 Handbook of Magnetic Materials (Buschow K H J, ed.) (Amsterdam: North-Holland) Vol. 17

[4] Shen B G, Sun J R, Hu F X, Zhang H W and Cheng Z H 2009 Adv. Mater. 214545

[5] Pecharsky V K and Gschneidner K A Jr 1997 Phys. Rev. Lett. 784494

[6] Hu F X, Shen B G, Sun J R and Zhang X X 2000 Chin. Phys. 9550

[7] Hu F X, Shen B G, Sun J R, Cheng Z H, Rao G H and Zhang X X 2001 Appl. Phys. Lett. $\mathbf{7 8} 3675$

[8] Fujita A, Fujieda S, Hasegawa Y and Fukamichi K 2003 Phys. Rev. B 67104416

[9] Shen B G, Hu F X, Dong Q Y and Sun J R 2013 Chin. Phys. B 22 017502

[10] Tegus O, Brück E, Buschow K H J and de Boer F R 2002 Nature 415 150

[11] Hu F X, Shen B G and Sun J R 2000 Appl. Phys. Lett. 763460

[12] Hu F X, Shen B G, Sun J R and Wu G H 2001 Phys. Rev. B 64132412

[13] Krenke T, Duman E, Acet M, Wassermann E F, Moya X, Mañosa L and Planes A 2005 Nature Mater. 4450

[14] Mañosa L, González-Alonso D, Planes A, Bonnot E, Barrio M, Tamarit J L, Aksoy S and Acet M 2010 Nature Mater. 9478

[15] Liu J, Gottschall T, Skokov K P, Moore J D and Gutfleisch O 2012 Nature Mater. 11620

[16] Planes A, Mañosa L and Acet M 2009 J. Phys.: Condens. Matter 21 233201

[17] Chen Y F, Wang F, Shen B G, Hu F X, Cheng Z H, Wang G J and Sun J R 2002 Chin. Phys. 11741

[18] Wang F, Chen Y F, Wang G J, Sun J R and Shen B G 2003 Chin. Phys. 12911

[19] Wang F, Chen Y F, Wang G J, Sun J R and Shen B G 2004 Chin. Phys. 13393

[20] Wang G J, Hu F X, Wang F and Shen B G 2004 Chin. Phys. 13546

[21] Wang F, Chen Y F, Wang G J, Sun J R and Shen B G 2004 Chin. Phys. 131344

[22] Hu F X, Qian X L, Wang G J, Sun J R, Shen B G, Cheng Z H and Gao J 2005 Chin. Phys. 142329

[23] Marcos J, Planes A, Manosa L, Casanova F, Batlle X, Labarta A and Martinez B 2002 Phys. Rev. B 66224413

[24] Khovailo V V, Takagi T, Tani J, Levitin R Z, Cherechukin A A, Matsumoto M and Note R 2002 Phys. Rev. B 65092410

[25] Marcos J, Mañosa L, Planes A, Casanova F, Batlle X and Labarta A 2003 Phys. Rev. B 68094401

[26] Pareti L, Solzi M, Albertini F and Paoluzi A 2003 Euro. Phys. J. B 32 303 
[27] Pasquale M, Sasso C P, Lewis L H, Giudici L, Lograsso T and Schlagel D 2005 Phys. Rev. B 72094435

[28] Biswas C, Rawat R and Barman S R 2005 Appl. Phys. Lett. 86202508

[29] Stadler S, Khan M, Mitchell J, Ali N, Gomes A M, Dubenko I, Takeuchi A Y and Guimarães A P 2006 Appl. Phys. Lett. 88192511

[30] Han Z D, Wang D H, Zhang C L, Tang S L, Gu B X and Du Y W 2006 Appl. Phys. Lett. 89182507

[31] Moya X, Manosa L, Planes A, Krenke T, Acet M, Morin M, Zarestky J L and Lograsso T A 2006 Phys. Rev. B 74024109

[32] Han Z D, Wang D H, Zhang C L, Xuan H C, Gu B X and Du Y W 2007 Appl. Phys. Lett. 90042507

[33] Roy S, Blackburn E, Valvidares S M, Fitzsimmons M R, Vogel S C, Khan M, Dubenko I, Stadler S, Ali N, Sinha S K and Kortright J B 2009 Phys. Rev. B 79235127

[34] Heusler F, Starck W and Haupt E 1903 Verh. Phys. Ges. 5220

[35] Hames F A 1960 J. Appl. Phys. 31 S307

[36] Webster P J 1968 (PhD thesis) (University of Sheffield)

[37] Soltys J 1974 Acta Phys. Pol. A 46383

[38] Kubler J, Williams A R and Sommers C B 1983 Phys. Rev. B 281745

[39] L'vov V A, Gomonaj E V and Chernenko V A 1998 J. Phys.: Condens. Matter 104587

[40] Krenke T, Acet M, Wassermann E, Moya X, Mañosa L and Planes A 2005 Phys. Rev. B 72014412

[41] Krenke T, Acet M, Wassermann E, Moya X, Mañosa L and Planes A 2006 Phys. Rev. B 73174413

[42] Brown G V 1976 J. Appl. Phys. 473673

[43] Lee J S 2004 Phys. Stat. Sol. (b) 2411765

[44] Ullakko K, Huang J K, Kantner C and O'Handley R C 1996 Appl. Phys. Lett. 691966

[45] Vasil'ev A N, Bozhko A D and Khovailo V V 1999 Phys. Rev. B 59 1113

[46] Hu F X, Sun J R, Wu G H and Shen B G 2001 J. Appl. Phys. 905216

[47] Kainuma R, Imano Y, Ito W, Sutou Y, Morito H, Okamoto S, Kitakami O, Oikawa K, Fujita A, Kanomata T and Ishida K 2006 Nature 439957

[48] Karaca H E, Karaman I, Basaran B, Ren Y, Chumlyakov Y I and Maier H J 2009 Adv. Funct. Mater. 19983

[49] Ma L, Zhang H W, Yu S Y, Zhu Z Y, Chen J L, Wu G H, Liu H Y, Qu J P and Li Y X 2008 Appl. Phys. Lett. 92032509

[50] Kainuma R, Ito W, Umetsu R Y, Oikawa K and Ishida K 2008 Appl. Phys. Lett. 93091906

[51] Yu S Y, Liu Z H, Liu G D, Chen J L, Cao Z X, Wu G H, Zhang B and Zhang X X 2006 Appl. Phys. Lett. 89162503

[52] Sharma V K, Chattopadhyay M K, Shaeb K H B, Chouhan A and Roy S B 2006 Appl. Phys. Lett. 89222509

[53] Chen L, Hu F X, Wang J, Bao L F, Sun J R, Shen B G, Yin J H and Pan L Q 2012 Appl. Phys. Lett. 101012401

[54] Chen L, Hu F X, Wang J, Bao L F, Zheng X Q, Pan L Q, Yin J H, Sun J R and Shen B G 2013 J. Alloy. Compd. 549170

[55] Chen L, Hu F X, Wang J, Zhao J L, Sun J R, Shen B G, Yin J H and Pan L Q 2011 J. Phys. D: Appl. Phys. 44085002

[56] Chen L, Hu F X, Wang J, Shen J, Zhang J, Sun J R, Shen B G, Yin J H and Pan L Q 2010 J. Appl. Phys. 107 09A940

[57] Xuan H C, Wang D H, Zhang C L, Han Z D, Gu B X and Du Y W 2008 Appl. Phys. Lett. 92102503
[58] Du J, Zheng Q, Ren W J, Feng W J, Liu X G and Z D Zhang 2007 J. Phys. D: Appl. Phys. 405523

[59] Hu F X, Wang J, Chen L, Zhao J L, Sun J R and Shen B G 2009 Appl. Phys. Lett. 95112503

[60] Zhao X G, Li B, Hsieh C C, Chang W C, Liu W and Zhang Z D 2012 IEEE Transactions on Magnetics 483742

[61] Yu S Y, Yan S S, Kang S S, Tang X D, Qian J F, Chen J L and Wu G H 2011 Scr. Mater. 659

[62] Xuan H C, Xie K X, Wang D H, Han Z D, Zhang C L, Gu B X and Du Y W 2008 Appl. Phys. Lett. 92242506

[63] Chen L, Hu F X, Wang J, Shen J, Sun J R, Shen B G, Yin J H, Pan L Q and Huang Q Z 2011 J. Appl. Phys. 109 07A939

[64] Li B, Ren W J, Zhang Q, Lv X K, Liu X G, Meng H, Li J, Li D and Zhang Z D 2009 Appl. Phys. Lett. 95172506

[65] Gao B, Hu F X, Shen J, Wang J, Sun J R and Shen B G 2009 J. Appl. Phys. 105083902

[66] Hu F X, Wang J, Shen J, Gao B, Sun J R and Shen B G 2009 J. Appl. Phys. 105 07A939

[67] Gao B, Shen J, Hu F X, Wang J, Sun J R and Shen B G 2009 Appl. Phys. A 97443

[68] Gao B, Hu F X, Shen J, Wang J, Sun J R and Shen B G 2009 J. Magn. Magn. Mater. 3212571

[69] Ito W, Nagasako M, Umetsu R Y, Kainuma R, Kanomata T and Ishida K 2008 Appl. Phys. Lett. 93232503

[70] Kustov S, Corr'o M L, Pons J and Cesari E 2009 Appl. Phys. Lett. 94 191901

[71] Krenke T, Duman E, Acet M, Wassermann F, Moya X, Mañosa L, Planes A, Suard E and Ouladdiaf B 2007 Phys. Rev. B 75104414

[72] Liu G J, Sun J R, Shen J, Gao B, Zhang H W, Hu F X and Shen B G 2007 Appl. Phys. Lett. 90032507

[73] Balli M, Fruchart D, Gignoux D and Zach R 2009 Appl. Phys. Lett. 95 072509

[74] Wang W H, Chen J L, Liu Z H, Wu G H and Zhan W S 2001 Phys. Rev. $B \mathbf{6 5} 012416$

[75] Aksoy S, Acet M, Deen P P, Mañosa L and Planes A 2009 Phys. Rev. B 79212401

[76] Zhang Y Q, Zhang Z D and Aarts J 2004 Phys. Rev. B 70132407

[77] Deng Y and Ansell G S 1990 Acta Metall. Mater. 3869

[78] Ortin J and Delaey L 2002 Int. J. Non-Linear Mech. 371275

[79] Yu S Y, Cao Z X, Ma L, Liu G D, Chen J L, Wu G H, Zhang B and Zhang X X 2007 Appl. Phys. Lett. 91102507

[80] Itsumi Y and Ellis D E 1996 J. Mater. Res. 112206

[81] Muldawer L 1966 J. Appl. Phys. 372062

[82] Murakami Y, Watanabe Y and Kachi S 1980 Transactions of the Japan Institute of Metals 21708

[83] Webster P J, Ziebeck K R A, Town S L and Peak M S 1984 Phil. Mag. B 49295

[84] Entel P, Buchelnikov V D, Khovailo V V, Zayak A T, Adeagbo W A, Gruner M E, Herper H C and Wassermann E F 2006 J. Phys. D: Appl. Phys. 39865

[85] Enkovaara J, Heczko O, Ayuela A and Nieminen R M 2003 Phys. Rev. B 67212405

[86] Umetsu R Y, Sheikh A, Ito W, Ouladdiaf B, Ziebeck K R A, Kanomata T and Kainuma R 2011 Appl. Phys. Lett. 98042507 